\title{
Mood, definiteness and specificity: a linguistic and a philosophical account of their similarities and differences
}

\author{
JAN RIJKHOFF \\ Department of Linguistics, University of Aarhus, Denmark
}

JOHANNA SEIBT

Department of Philosophy, University of Aarhus, Denmark \& University of Konstanz, Germany

\begin{abstract}
In diesem Beitrag beschreiben wir aus linguistischer Perspektive das Verhältnis von einigen grammatischen Kategorien des Satzes (Realis) und der Nominalphrase (Definitheit, Spezifizität) im Hinblick auf den Status ihrer Referenten in der Diskurswelt, und überlegen anschliessend die ontologische Signifikanz der linguistischen Fakten. Unser Zugang unterscheidet sich in drei wichtigen Hinsichten von vorliegenden Arbeiten. Wir bieten erstens eine Erklärung für die symmetrischen und anti-symmetrischen (invers symmetrischen) Beziehungen, die zwischen Realis (bzw. Irrealis) und Definitheit (bzw. Indefinitheit) bestehen. Zweitens zeigen wir, dass keine Erklärung dieser Beziehungen ohne den Einbezug der grammatischen Kategorie der Spezifizität auskommen kann. Schliesslich untersuchen wir, in welchem Mass die inferentiellen Aspekte der linguistischen Symmetrien und Anti-Symmetrien ontologisch relevant sind, welche Schwierigkeiten sie für das ontologische Standardverständnis von Possibilia aufwerfen, und zeigen, dass eine Ontologie, die mit dynamischen und unbestimmt lokalisierten Individuen verfährt, den linguistischen Daten offenbar besser gerecht wird.
\end{abstract}


JAN RIJKHOFF AND JOHANNA SEIBT

\section{INTRODUCTION}

The linguistic literature of the last couple of decades contains several observations concerning morphological or semantic similarities between (markers of) mood and definiteness. ${ }^{1}$ Some attempts have been made to account for these similarities, but in our view these attempts are all flawed in that they (a) focus on symmetrical relationships between grammatical categories in the clause and in the noun phrase, i.e. they largely ignore the systematic dissimilarities or inverse symmetries (which we call here 'anti-symmetries' for short), and (b) fail to properly distinguish between definite/indefinite reference on the one hand and specific/nonspecific reference on the other. In this contribution we deal with both symmetrical and anti-symmetrical relationships between mood and definiteness and contend that any account of these relationships is incomplete without acknowledging the crucial role of specificity.

As to symmetry, it is argued that the categories 'realis' and 'irrealis' at the level of the clause are similar to the categories 'definite' and 'nonspecific-indefinite' at the level of the noun phrase. 'Realis' and 'definite' indicate that the entity (thing, event) is 'grounded' in the world of discourse. By contrast, 'irrealis' and 'nonspecific-indefinite' signal that the entity (thing, event) does not have a location (is not 'grounded') in the world of discourse. There are thus two symmetries, one linking the grammatical categories realis and definiteness, the other linking irrealis and nonspecific-indefiniteness.

There is also an interesting anti-symmetry between (in)definiteness and (ir)realis (Rijkhoff 1988), which has to do with the number of ways that an entity can be definite (thing) or less than completely actual (event). Here definite aligns with irrealis in that both definite things (referents of definite noun phrases) and nonactual events (referents of irrealis clauses) can occur in the world of discourse for many different reasons. By contrast, referents of specific-indefinite noun phrases and referents of realis clauses exist in the world of discourse for one and the same reason: because they 'ground' themselves in the world of discourse when they are being referred to for the first time.

The paper is organized as follows. Section 2 discusses parallels between the structure of the noun phrase (NP) and the structure of the clause; evidence for parallels between the semantic (layered) structure of the noun phrase and the 
clause is offered in section 3. Section 4 is concerned with the categories (ir)realis and (in)definiteness. Similarities between (ir)realis mood and (in)definiteness are the topic of section 5, whereas the differences are dealt with in section 6 . Section 7 shows that symmetrical as well as anti-symmetrical relations between mood and definiteness can only be explained if we bring into the discussion another grammatical category of the NP: specificity. Sections 8-11 discuss the philosophical implications of our observations and show that process ontological theories are better equipped to deal with symmetries and antisymmetries between things and events than substance based ontologies. ${ }^{2}$

\section{Parallels betWeEN NPS AND SENTENCES}

Both in functional and formal theories of grammar it has been argued that NPs and clauses can be analyzed in a similar fashion. Whereas formal frameworks are concerned with similarities in the syntactic structure of NPs and clauses, functional theories have focused on parallels between semantic representations of these linguistic units. In the framework of Functional Grammar (Dik 1997) such parallels were first discussed in Rijkhoff (1988) and they will be briefly presented below (for a more elaborate presentation the reader is referred to Rijkhoff 2002).

\subsection{Descriptive modifiers}

Modifiers in the noun phrase and in the clause can be divided in two major types: descriptive and interpersonal modifiers. Descriptive modifiers specify properties of the referent of the NP in terms of quality, quantity and location (but see note 4). By contrast, interpersonal or 'discourse' modifiers (discussed in section 1.2.) pertain to 'that it is', i.e. they are concerned with the referential status of entities (objects, events) in the shared world of discourse ( \pm Grounded). ${ }^{3}$ The distinction between descriptive and interpersonal modifiers reflects the double function of NPs and clauses: on the one hand they provide a physical description of an entity (thing, event) and on the other hand they are constructions that speakers use to refer to an entity.

There are three descriptive layers of modification, each of which has slots for grammatical and lexical modifiers (Figure 1). ${ }^{4}$ Adnominal adjectives, possessives and relative clauses are examples of lexical modifiers or 'satellites', because they involve members of lexical categories (verbs, nouns, adjectives, adverbs). 
Operator slots are reserved for grammatical (i.e. non-lexical) modifiers which can be expressed as free forms (e.g. articles, demonstratives) or by inflectional morphology (e.g. definiteness, number, tense, aspect, mood, illocutionary force).

Grammatical expression of Quality, Quantity and Location in the clause

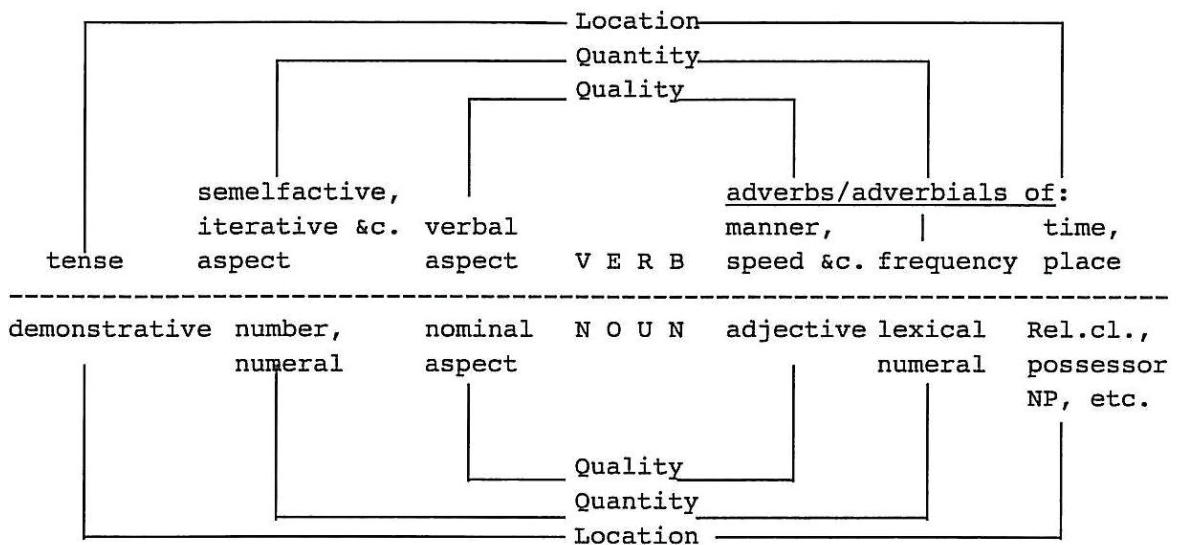

Grammatical expression of Quality Quantity and Location in the NP
Lexical expression of Quality, Quantity and Location in the clause

Lexical expression of Quality Quantity and Location in the NP

Figure 1. Symmetry in the underlying structure of the clause and the NP: descriptive modifiers

The quality layer contains the head (noun, verb) and accommodates modifiers that only relate to the property that is designated by the head (qualifying modifiers), such as nominal or verbal aspect markers, (typically) adjectives (if a language has them), and adverb(ial)s of manner or speed. The quantity layer contains the quality layer and accommodates modifiers (quantifying modifiers) having to do with number distinctions (singular, plural) or cardinality. The location layer contains both the quality layer and the quantity layer and accommodates modifiers specifying properties concerning the location of the thing or event (localizing modifiers), such as demonstratives, tense markers, relative clauses, adverb(ial)s such as in the garden, yesterday.

For example, in the NP those two black dogs on the carpet the qualifying modifier black only relates to the noun $d o g$, not the quantity or the location. The quantifying modifier two specifies the number of black dog entities, not the number of locations; and both those and on the carpet specify the location of the dog entities with all their qualitative and quantitative properties. 
MOOD, DEFINITENESS AND SPECIFICITY: A LINGUISTIC AND A PHILOSOPHICAL ACCOUNT OF THEIR SIMILARITIES AND DIFFERENCES

Languages use only a subset of the modifier categories mentioned in Figure 1 and it must be emphasized that there is no one-to-one relationship between the form and the function of a modifier. We shall see below, for example, that demonstratives can also serve as interpersonal operators and that relative clauses can be employed as qualifying, quantifying or localizing satellites.

\subsection{Interpersonal or discourse modifiers}

In addition to the various descriptive layers, the underlying structures of the clause and the NP contain a single layer to accommodate modifiers that are concerned with the status of the thing or event as a discourse entity (interpersonal modifiers). Here we find markers of \pm definiteness, \pm specificity; \pm realis (actual/non-actual), modifiers/adverb(ial)s such as same, other, really, and actually. In the layered model of the clause and of the NP, interpersonal modifiers appear in the outermost layer, as they have all descriptive modifiers in their scope (Figure 2):

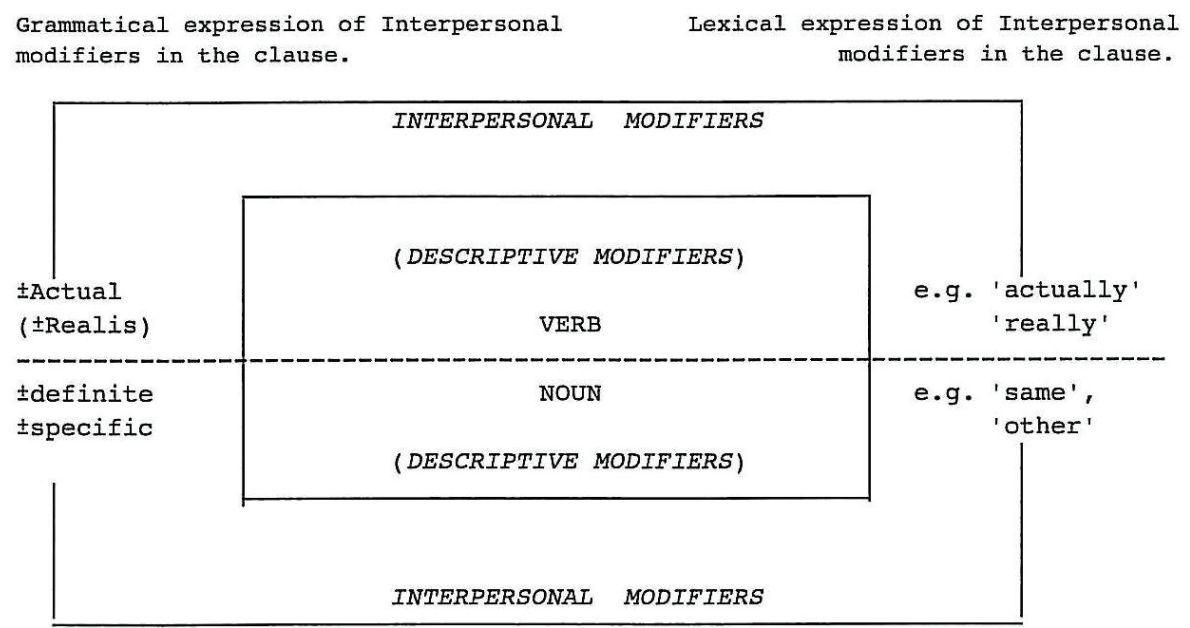

Grammatical expression of Interpersonal Lexical expression of Interpersonal modifiers in the NP. modifiers in the NP.

Figure 2. Symmetry in the underlying structure of the clause and the NP: interpersonal modifiers

\section{EVIDENCE FOR THE LAYERED STRUCTURE}

The layered model presented above is supported by various kinds of data. Here we will briefly mention evidence from morphosyntax, parts-of-speech systems, historical linguistics, and cognitive linguistics. 


\subsection{Morphosyntax}

Logically, there are 24 possible ways to linearize a noun, a demonstrative, numeral, and an adjective in the noun phrase, but not every possible combination occurs in the languages of the world. Interestingly there are no gaps in the eight 'iconic' combinations, i.e. patterns that reflect the layered organization of the NP presented above (with the adjective always next to the noun and the demonstrative always in the periphery; see Rijkhoff 2004):

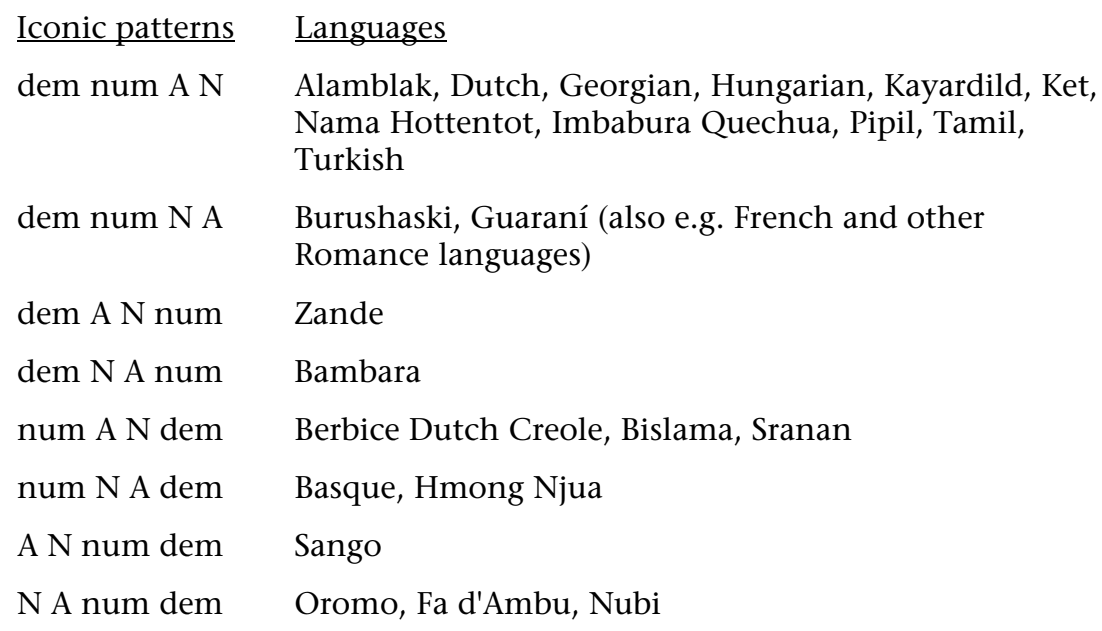

By contrast, languages that employ one of the remaining 16 non-iconic patterns as the basic order seem to be extremely rare.

(2) Non-iconic patterns

$\begin{array}{cccc}\text { num A dem N } & \text { A num N dem } & \text { dem N num A } & \text { N dem num A } \\ \text { A num dem N } & \text { num dem N A } & \text { num N dem A } & \text { N num dem A } \\ \text { A dem num N } & \text { A dem N num } & \text { A N dem num } & \text { N A dem num } \\ \text { dem A num N } & \text { num dem A N } & \text { N num A dem } & \text { N dem A num }\end{array}$

Greenberg (1966: 86-87) already mentioned that there is a clear preference for the iconic patterns:

Universal 20

When any or all of the items (demonstrative, numeral, and descriptive adjective) precede the noun, 
MOOD, DEFINITENESS AND SPECIFICITY: A LINGUISTIC AND A PHILOSOPHICAL ACCOUNT OF THEIR SIMILARITIES AND DIFFERENCES

they are always found in that order. If they follow, the order is either the same or its exact opposite.

The reason Greenberg had to allow for a non-iconic pattern at all was actually due to one language in his sample, Kikuyu, which has the order [N dem num A]. According to Seiler (1978: 322), however, this is a "less popular variant" in Kikuyu, the normal order being [N A num dem].

Hawkins (1983), whose sample contained over 300 languages, mentioned two other Bantu languages with a non-iconic basic pattern in the NP: Aghem [N A dem num] and Noni (which has [N dem num A] as well as [N dem A num]), both spoken in Cameroon. Consequently Hawkins (1983: 119-120) reformulated Greenberg's Universal 20 as follows: ${ }^{5}$

\section{Universal 20'}

When any or all of the items (demonstrative, numeral, and descriptive adjective) precede the noun, they (i.e., those that do precede) are always found in that order. For those that follow, no predictions are made, though the most frequent order is the mirrorimage of the order for preceding modifiers. In no case does the adjective precede the head when the demonstrative or numeral follow.

Thus, whereas each iconic pattern is employed as the basic order in at least one of the world's languages, only a small fraction of the 16 non-iconic orders has been found so far. It remains to be seen, however, if we are really dealing with integral NPs in the case of Kikuyu, Aghem and Noni (see Rijkhoff 2002: 272-276 for some arguments to show that we may not be dealing with simple integral NPs in the case of non-iconic patterns).

There is also evidence from morphology and clause internal syntax to support the layered model (Figure 1). In English, for example, different kinds of temporal satellites tend to occur in the order time duration (for a short while = qualifying

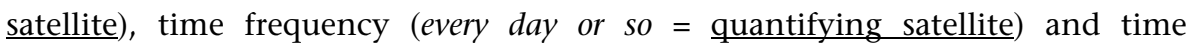
position (in January = localizing satellite), as in (Quirk et al. 1985: 551):

\section{I was there for a short while every day or so in January}


In her 1985 monograph on morphology, Bybee (1985: 196) investigated the ordering of inflectional morphemes relative to the verb in a representative sample of fifty languages. She found that "[...] aspect occurs closest to the stem, followed by tense, and then by mood. The only exception to this ordering found in the 50-language sample is in Ojibwa, where the Dubitative suffix precedes the Preterite suffix."

\subsection{Diachronic connections}

There is also historical evidence to support a parallel analysis in the layered representation of the clause and the noun phrase. For example, Gildea (1993) has shown how demonstratives have developed into tense markers in Panare (both: 'location'). Several studies have remarked on phonological similarities between markers of nominal and verbal plurality (both: 'quantity' - cf. Frajzyngier 1977, 1997; Mithun 1988; Newman 1990) and von Garnier discussed historical connections between markers of collectivity and perfectivity (both: 'quality') as early as 1909 (von Garnier 1909).

\subsection{Metaphor}

An obvious question to ask in this context is why there should be parallels between the underlying semantic structure of the NP and clause in the first place (see also sections 8-11). Basically there are four possible answers to this question:

1. Clause structure is derived from NP structure;

2. NP structure is derived from clause structure;

3. NP structure and clause structure are due to a single cognitive procedure that deals with spatio-temporal entities;

4. any similarities are due to chance (zero hypothesis).

Currently the first possibility has the best empirical foundation. Although relatively little is known about the way the human cognitive system processes spatial and temporal entities, linguistic evidence indicates that our conceptual system is largely metaphorical in nature (Lakoff 1987). Since there are many examples which show that spatial metaphors are used to express temporal and other non-spatial notions, it is assumed that spatial conception plays a fundamental role in human cognition (Lyons 1977: 718; Claudi \& Heine 1986; 
MOOD, DEFINITENESS AND SPECIFICITY: A LINGUISTIC AND A PHILOSOPHICAL ACCOUNT OF THEIR SIMILARITIES AND DIFFERENCES

Levinson 1992; Heine 1997; Haspelmath 1997). Thus perhaps it is because temporal entities are understood in terms of (cognitively less complex) spatial entities that NPs and clauses can be analyzed in a similar fashion (this assumption may, however, reflect a eurocentric perspective - see the Koasati example in note 7 below).

It is perhaps good to point out that the time-is-like-space metaphor does not necessarily imply that operators of the noun develop into operators of the verb (as suggested by Newman 1990: 118 in the case of quantifying operators in Chadic). ${ }^{6}$ Rather it seems that operators of the noun and the clause both originate from a spatial element outside the NP proper. For example, the Panare tense marker mentioned above developed from a free demonstrative pronoun and is has been argued repeatedly that the free demonstrative pronoun is also the diachronic source for the adnominal demonstrative pronoun (McCool 1984, 1993; Lehmann 1995: 37-39; Moravcsik 1997: 319).

\subsection{Isomorphism I: lexical modifiers in the NP and in the clause}

Languages across the globe employ various kinds of parts-of-speech systems (Figure 3). When we restrict ourselves to lexical word classes, we find, for example, that some languages have one major word class (Type 1 - Samoan), whereas other have several (Type 4 - e.g. Hungarian).

\begin{tabular}{|l||l||c|c|c|c|}
\hline \multirow{2}{*}{$\begin{array}{l}\text { Flexible } \\
\text { parts-of-speech } \\
\text { systems }\end{array}$} & Type 1 & \multicolumn{4}{|c|}{ contentive } \\
\cline { 2 - 6 } & Type 2 & \multicolumn{3}{|c|}{ verb } & \multicolumn{2}{|c|}{ non-verb } \\
\cline { 2 - 6 } & Type 3 & verb & noun & modifier \\
\hline \multirow{2}{*}{$\begin{array}{l}\text { Rigid } \\
\text { parts-of-speech } \\
\text { systems }\end{array}$} & Type 4 & verb & noun & adjective & adverb \\
\cline { 2 - 6 } & Type 5 & verb & noun & adjective \\
\cline { 2 - 5 } & Type 6 & \multicolumn{2}{|c|}{ verb } & \multicolumn{2}{|c|}{ noun } \\
\cline { 2 - 5 } & Type 7 & \multicolumn{4}{|c|}{ verb } \\
\hline
\end{tabular}

Figure 3. Hengeveld's parts-of-speech system (adverb = manner adverb; based on Hengeveld, Rijkhoff and Siewierska 2004)

Apart from quantitative differences in their parts-of-speech systems (number of word classes), languages may also differ with respect to the degree of flexibility displayed by the members of a certain word class. For example, in English the adjective beautiful needs to be provided with an adverbializing suffix -ly before it can modify a verb: 
(4) She recorded a beautiful song

(5) She sang beautifully

But there are also languages, such as Ngiti (Type 3), which do not distinguish between adjectives and (manner) adverbs; i.e. Ngiti has a single class of flexible items ('modifiers') that can be used to modify verbs or nouns (Kutsch Lojenga 1994: 336):

"There is no morphological nor a clear syntactic distinction between a class of adjectives and a class of adverbs in Ngiti. The functional term modifiers is therefore used [...] to cover a fairly large grammatical class of words, containing about 150 items, which are neither nouns nor verbs and which all have a modifying function in relation to different constituents."

Ngiti (Kutsch Lojenga 1992: 338)

(6)

$\begin{array}{lllll}\text { ngbángba } & \text { nítdù } & & \text { issó } & \text { ànò } \\ \text { ngbángba } & n \dot{t} & \text {-ìtdù } & \text { issó } & \text { ànò } \\ \text { child } & \text { RSM } & \text {-carry:PF.PR } & \text { light } & \text { load }\end{array}$

'The child carried a light load'

(7) isś

$\begin{array}{lllll}\text { isś } & \text { ngbángba } & \text { nítdù } & & \text { ànò } \\ \text { issó } & n g b a ́ n g b a & n \dot{t} & \text {-ìtdù } & \text { ànò } \\ \text { light } & \text { child } & \text { RSM } & \text {-carry:PF.PR load }\end{array}$

'The child carried the load easily'

In other words, Ngiti and other languages of Type 3 the same element is used as a qualifying modifier ('quality satellite') in the NP and in the clause.

\subsection{Isomorphism II: grammatical modifiers in the NP and in the clause}

It was already mentioned in section 3.2 that there is a strong resemblance between quantifying operators in the NP and the clause in certain languages. The same goes for operators at the interpersonal level. Compare, for example, the 'multifunctional determiners' in Haitian Creole and Fongbe (a Kwa language 
MOOD, DEFINITENESS AND SPECIFICITY: A LINGUISTIC AND A PHILOSOPHICAL ACCOUNT OF THEIR SIMILARITIES AND DIFFERENCES

mainly spoken in Benin and one of the substratum languages of Haitian Creole): ${ }^{7}$

Haitian Creole and Fongbe (Lefebvre 1998: 94, 99)

(8)

$\begin{array}{llccc}\text { a. Haitian } & M & \text { manje } & k r a b & l a \\ \text { b. Fongbe } & N & d u ́ & \text { àsón } & \text { ś } \\ & \text { I } & \text { eat } & \text { crab } & \text { DET } \\ & \text { 'I ate the crab (in question/that we know of)' }\end{array}$

(9)
a. Haitian Jan
rive
$a$
b. Fongbe Jan
wá
j
John
arrive
DET

'Actually, John arrived'

\section{MOOD AND DEFINITENESS}

Having dealt with the preliminaries, we can now begin our discussion of the main topic of this paper: the relationship between interpersonal operators mood and definiteness (and ultimately: specificness). Formal evidence for a relationship between definiteness and (realis) mood was already provided in the previous section (see examples (8) and (9) from Fongbe and Haitian Creole; see also examples (29) and (30) from Jacaltec below).

Sections 4.1 and 4.2 briefly discuss the categories (ir)realis and (in)definiteness. Similarities between (i) 'realis' and 'definite' and (ii) 'irrealis' and 'indefinite' will be explored in section 4.3. The anti-symmetrical relationship between interpersonal operators of the NP and the clause is the topic of section 5, which brings into the discussion another grammatical category of the NP: specificity. ${ }^{8}$

\subsection{Realis and irrealis mood}

An event that is being referred to may be actual (or 'real' in the sense of 'having been initiated' or 'having occurred' in the world) or non-actual ('irreal'). Events may be perceived as non-actual for different reasons; for example, because the speaker expresses a wish or a request:

(10) I wish you were here [interlocutors are not in the same place] 
(11) Would you please close the door? [the door is not closed]

In both cases the speaker refers to an event that has not happened (yet) and which therefore cannot be located at a particular spatio-temporal region in the world. ${ }^{9}$

All languages seem to have linguistic devices to mark the various kinds of moods (e.g. epistemic, deontic) and speech acts (e.g. indicative, imperative, optative) that signal in a more or less indirect fashion to the addressee whether or not reference is being made to an actual event. ${ }^{10}$ There are, however, quite a few languages that (also) employ a special realis or irrealis marker to indicate whether or not the event referred to is to be regarded as actual or non-actual. Elliott (2000: 68-70) mentions four broad contexts in which such a marker tends to appear: (i) potential events, (ii) events whose occurrence is dependent on certain conditions being fulfilled (conditionals), including counterfactuals, (iii) events which are qualified by modality, and (iv) commands. In addition she mentions three other semantic contexts where a special irrealis marker may occur: (v) negation, (vi) habituals, and (vii) interrogatives. The following examples from the Papuan language Amele illustrate.

Amele $(\mathrm{R}=$ realis, IRR = irrealis; Roberts 1990: 371-372)

$\begin{array}{llll}\text { Ho } & \text { bu-busal-en } & \text { age } & \text { qo-in } \\ \text { pig } & \text { SIM-run.out-3SG.DS.R } & \text { 3PL } & \text { hit-3PL-REM.PAST }\end{array}$

'They killed the pig as it ran out (before today)'

$\begin{array}{llll}\text { Ho } & \text { bu-busal-en } & \text { age } & \text { qo-igi-a } \\ \text { pig } & \text { SIM-run.out-3SG.DS.R } & \text { 3PL } & \text { hit-3PL-PRESENT }\end{array}$

'They are killing the pig as it runs out'

\begin{tabular}{|c|c|c|c|}
\hline (14) $\mathrm{Ho}$ & $b u$-busal-eb & age & qo-qag-an \\
\hline pig & SIM-run.out-3SG.DS.IRR & 3PL & hit-3PL-FUTURE \\
\hline
\end{tabular}

'They will kill the pig as it runs out' 
MOOD, DEFINITENESS AND SPECIFICITY: A LINGUISTIC AND A PHILOSOPHICAL ACCOUNT OF THEIR SIMILARITIES AND DIFFERENCES

$\begin{array}{llll}\text { Ho } & \text { bu-busal-eb } & \text { age } & q u \text {-ig- } a \\ \text { pig } & \text { SIM-run.out-3SG.DS.IRR } & \text { 3PL } & \text { hit-3PL-IMP }\end{array}$

'Kill the pig as it runs out!'

(16) Ho bu-busal-eb

cain qu-wain

pig SIM-run.out-3SG.DS.IRR PROH hit-NEG.F.3PL

'Don't kill the pig as it runs out!'

(17)

$\begin{array}{lllll}\text { Ho } & \text { bu-busal-eb } & \text { ege } & q-o c & n u \\ \text { pig } & \text { SIM-run.out-3SG.DS.IRR } & \text { 1PL } & \text { hit-INF } & \text { HORT }\end{array}$

'Let's kill the pig as it runs out!'

$\begin{array}{llll}\text { Ho } & b u \text {-busal-eb } & a g e & q o-u-b \\ \text { pig } & \text { SIM-run.out-3SG.DS.IRR } & \text { 3PL } & \text { hit-COUNTERF-PL }\end{array}$

'They would/should have killed the pig as it ran out'

\subsection{Definiteness and indefiniteness}

There is no shortage of semantic, pragmatic or cognitive accounts of the grammatical categories definiteness and indefiniteness (see e.g. Hawkins 1978, Lyons 1999, Epstein 2002). The vast literature on the subject shows, among other things, that opinions differ as to whether definiteness is explained best in terms of identifiability, familiarity or accessibility. We will not defend any particular position here; our main point is to show that (at some level of abstraction) the notions definiteness and indefiniteness can be compared to the notions realis and irrealis in that both pairs have to do with the pragmatic status of the referent (thing, event) in the world of discourse. For this reason it will suffice to mention the contexts in which definite NPs are commonly used.

Definite NPs are perhaps most typically used when reference is made to an entity that is already available in world of discourse and which has been mentioned not long before (anaphoric use), as in:

(19) I just bought a book and a calendar. Surprisingly, the book was much cheaper than the calendar 
Definite NPs are also typically used when the referent is available in the physical context (situational or deictic use).

(20) Now tell me - what do you see on the monitor?

Referents of NPs can also be deemed identifiable (or accessible) by the speaker because of so-called 'bridging-cross-reference' (associative use).

(21) I took a taxi from the station. On the way the driver told me there was a bus strike

Another well known context that licenses the use of a definite NP is when reference is made to an entity which is not directly available in the linguistic or non-linguistic context but which is relatively unique in the given contextual setting and which the hearer can often identify on the basis of his or her general knowledge. An example of this is the station in (21); here is another example:

(22) The moon was very bright last night

Compare with:

\section{(23) * The star was very bright last night}

Indefinite NPs, on the other hand, are used to refer to entities that are not deemed identifiable for the addressee, usually because they have not been properly introduced in the world of discourse (as is the case with all indefinite NPs in the examples above).

\section{REALIS AND DEFINITENESS: SIMILARITIES}

In the layered representation of the NP and the clause (Figure 2) the categories realis/irrealis and definite/indefinite are represented at the interpersonal level, as both are concerned with the pragmatic status of a referent (thing, event) in the shared world of discourse. By marking an event as real (or actual) or by marking a thing as definite, the speaker indicates to the addressee that the event or thing referred to (already) has a place in the world of discourse. Conversely, marking an event as unreal (or non-actual) or marking a thing as indefinite is an 
MOOD, DEFINITENESS AND SPECIFICITY: A LINGUISTIC AND A PHILOSOPHICAL ACCOUNT OF THEIR SIMILARITIES AND DIFFERENCES

indication for the addressee that the event or thing does not (yet) have a proper place in the world of discourse. ${ }^{11}$ In the case of a thing the hearer should interpret the indefiniteness marker as an instruction to construct a new spatial entity as a discourse referent. The irrealis marker also instructs the addressee to construe a new entity as a discourse referent (in this case a temporal entity: an event), but in addition the irrealis marker tells the addressee that the event must not be 'grounded' or 'anchored' as a real event in the world of discourse.

There are thus two symmetries, one linking Realis and Definiteness, the other linking Irrealis and Indefiniteness.

\begin{tabular}{|c|c|c||}
\hline NP (thing) & $\begin{array}{c}\text { OCCURRENCE IN WORLD } \\
\text { OF DISCOURSE }\end{array}$ & Clause (event) \\
\hline \hline \multirow{2}{*}{ Definite } & $\begin{array}{c}\text { THING OR EVENT (ALREADY) HAS A } \\
\text { LOCATION IN THE DISCOURSE } \\
\text { WORLD }\end{array}$ & Realis \\
\hline Indefinite & $\begin{array}{c}\text { THING OR EVENT DOES NOT HAVE A } \\
\text { LOCATION IN THE DISCOURSE } \\
\text { WORLD (YET) }\end{array}$ & Irrealis \\
\hline
\end{tabular}

Figure 4. Symmetry between Definite/Realis and Indefinite/Irrealis

\section{REALIS AND DEFINITENESS: DIFFERENCES}

There is also an interesting anti-symmetry between NPs and clauses which may point to a fundamental difference between first and second order (spatial and temporal) entities (Rijkhoff 1988: 25). ${ }^{12}$ We saw in section 4.2 that there are many reasons why the speaker may assume the referent of a definite NP to be recoverable for the hearer (anaphoric reference, deictic reference, etc.), but that there is basically only one way for an event to be actual: because it (has) occurred or is occurring. And vice versa: while there is basically one reason why the speaker assumes the referent of an indefinite NP to be irretrievable (because its referent is unidentifiable / unfamiliar / inaccessible), there are numerous reasons why an event can be non-actual. For example, because the speaker expresses a desire, a wish, a hope, a fear, an intention, a possibility, a probability, a request, or a command (see examples 14-18 from Amele). 


\begin{tabular}{|c|c|c|c|}
\hline $\begin{array}{l}\text { Noun } \\
\text { Phrase } \\
\text { (thing) }\end{array}$ & \multicolumn{2}{|c|}{$\begin{array}{c}\text { NUMBER OF REASONS FOR } \\
\text { BEING MARKED AS } \\
\text { (IN)DEFINITE OR (IR)REAL }\end{array}$} & $\begin{array}{l}\text { Clause } \\
\text { (event) }\end{array}$ \\
\hline Definite & MANY & ONE & Realis \\
\hline Indefinite & ONE & MANY & Irrealis \\
\hline
\end{tabular}

Figure 5. Anti-symmetry between Definite/Realis and Indefinite/Irrealis

\section{MORE ON THE RELATIONSHIP BETWEEN MOOD AND DEFINITENESS: THE ROLE OF 'SPECIFICITY'}

Sections 5 and 6 were concerned with symmetrical and anti-symmetrical relationships between (ir)realis mood and (in)definiteness. This section argues that we need another grammatical category of the NP so as to be able to give a more complete account of these (anti)symmetries: specificity. We will ignore the problem whether specificity is a subcategory of indefinite (the traditional view) or constitutes a separate mode of referring to entities (see note 8), since this issue does not affect the point we want to make: that specificity must play a crucial role in any account of the relationship between (ir)realis and (in)definiteness. Consider the following examples (Karttunen 1976):

Specific-indefinite reference:

\section{Max wants a dog. It is black}

\section{Nonspecific-indefinite reference:}

\section{(25) Max wants a dog. It must be black}

These examples show that there are two ways to continue the first sentence (Max wants a dog). The difference is due to the fact that in (24) reference is made to a specific dog ('Max wants a certain dog, which is known to be black'), whereas in (25) the speaker does not refer to any particular dog (see von Heusinger 2002b for a recent discussion of the notion specificness).

Before we continue, let us first return briefly to the realis/definiteness symmetry. Referents of clauses (events) and NPs (things) are both entities in the world of discourse created by the interlocutors. Many languages have special markers (e.g. 
MOOD, DEFINITENESS AND SPECIFICITY: A LINGUISTIC AND A PHILOSOPHICAL ACCOUNT OF THEIR SIMILARITIES AND DIFFERENCES

a realis affix as in examples $12-13$, or a definite article as in examples 19-22) to indicate that an event or thing exists (or already existed) and has a certain location in the world of discourse (or that its existence and location can be explained).

\section{Definite NP, realis clause}

\section{(26) I saw the movie in Amsterdam last week}

Since realis events and definite things are located in some spatio-temporal region in that world of discourse, these events and things can be said to be GROUNDED in that world of discourse. There is a difference, however, in that realis (tensed) events ground themselves upon being referred to by the speaker, whereas definite things often first need to be introduced by an indefinite NP before they can be grounded (hence the anti-symmetry).

Referents of irrealis clauses (see examples 14-18) and nonspecific-indefinite NPs (as in 25) are events and things that also may be said to exist in some fashion once they have been mentioned (since it is possible to refer to them anaphorically), but they do not occupy a particular spatio-temporal region in the world of discourse - at least not yet (it is impossible to say where or when they are occurring or have occurred). In other words, irrealis events and nonspecific-indefinite things are NOT GROUNDED in the world of discourse. ${ }^{13}$

This explains why tense marking ('location in time') is often obligatorily absent with certain modal distinctions. For instance, in Kobon "the tense distinctions between simple past, remote past, present, and future are made only in the indicative mood [...]" (Davies 1981: 168). However, non-actuality of an event does not necessarily mean that tense is always absent. When tense is used for a non-actual event, it specifies WHEN an event was non-actual. The following example from Nyigina (Australia) illustrates: 
Nyigina (Stokes 1982: 24)

$\begin{array}{ll}\text { marlu } & \text { wa-la-ma-na } \\ \text { NEG } & \text { 3SG-NONFUT.IRR-go-PAST }\end{array}$

burrula-nana

'He didn't go to Derby'

Derby-ALLAT

Referents of specific-indefinite NPs, on the other hand, are GROUNDED immediately in the world of discourse once they have been referred to by the speaker (see also 24$)^{14}$

Specific-indefinite reference:

(28) The other day my daughter saw a puppy in a pet shop. Of course, she wanted to take it home right away

In this sense referents of specific-indefinite NPs are like realis events in that they ground themselves (anti-symmetry). ${ }^{15}$

Summing up, we can now say that SYMMETRY between (in)definiteness and (ir)realis is due to the fact that

a) DEFINITE and REALIS indicate that the entity (thing, event) is grounded (occupies a certain spatio-temporal region) in the world of discourse, and

b) NONSPECIFIC-INDEFINITE and IRREALIS indicate that the entity (thing, event) is not grounded (does not occupy a certain spatio-temporal region) in the world of discourse.

\begin{tabular}{|c||c|c||}
\hline Noun Phrase (thing) & $\begin{array}{c}\text { OCCURRENCE IN } \\
\text { WORLD OF DISCOURSE }\end{array}$ & $\begin{array}{c}\text { Clause } \\
\text { (event) }\end{array}$ \\
\hline \hline Definite & $\begin{array}{c}\text { GROUNDED IN } \\
\text { DISCOURSE WORLD }\end{array}$ & Realis \\
\hline Nonspecific-indefinite & $\begin{array}{l}\text { NOT GROUNDED IN } \\
\text { DISCOURSE WORLD }\end{array}$ & Irrealis \\
\hline
\end{tabular}

Figure 6. Symmetry between Definite/Realis and Nonspecific-indefinite/Irrealis

In section 3.5 we saw that some languages use the same form to mark realis and definiteness (Fongbe, Haitian Creole). Jacaltec (Mayan) is an example of a 
MOOD, DEFINITENESS AND SPECIFICITY: A LINGUISTIC AND A PHILOSOPHICAL ACCOUNT OF THEIR SIMILARITIES AND DIFFERENCES

language that employs the same marker for irrealis and nonspecific-indefinite reference (variation due to vowel harmony): ${ }^{16}$

Jacaltec (Craig 1977: 93):

(29)

$\begin{array}{lll}\text { Way-oj } & a b & n a j \\ \text { sleep-OJ } & \text { EXH } & \text { CLF/he }\end{array}$

'Would that he slept!' [exhortative mood]

$\begin{array}{llllll}\text { (30) } & \text { X-Ø-'oc } & \text { heb } & \text { say- } a^{\prime} & \text { hun-uj } & \text { munlabel } \\ \text { ASP-ABS.3-start } & \text { PL } & \text { woman } & \text { look_for-FUT } & \text { a-OJ } & \text { pot }\end{array}$

'The women started looking for a pot' [nonspecific reference]

ANTI-SYMMETRY between (IN)DEFINITENESS and (IR)REALIS is due to the fact that

a) referents of DEFINITE NPs and referents of IRREALIS clauses are part of the world of discourse for many different reasons;

b) referents of SPECIFIC-INDEFINITE NPs and referents of REALIS clauses became part of the world of discourse for the same reason: because they 'ground' themselves in the world of discourse.

\begin{tabular}{|c|c|c|c|}
\hline $\begin{array}{l}\text { Noun } \\
\text { Phrase } \\
\text { (thing) }\end{array}$ & $\begin{array}{r}\text { NUMBER OF RF } \\
\text { MARKED } \\
\text { IN)DEFINIT }\end{array}$ & $\begin{array}{l}\text { ONS FOR BEING } \\
\text { (SPECIFIC } \\
\text { R (IR)REAL }\end{array}$ & $\begin{array}{l}\text { Clause } \\
\text { (event) }\end{array}$ \\
\hline Definite & MANY & $\begin{array}{c}\text { ONE } \\
\text { (GROUNDS ITSELF) }\end{array}$ & Realis \\
\hline $\begin{array}{l}\text { Specific- } \\
\text { indefinite }\end{array}$ & $\begin{array}{c}\text { ONE } \\
\text { (GROUNDS ITSELF) }\end{array}$ & MANY & Irrealis \\
\hline
\end{tabular}

Figure 7. Anti-symmetry between Definite/Realis and Specific-indefinite/Irrealis

\section{ONTOLOGY AND COGNITIVE SIGNIFICANCE}

So far we have highlighted parallels in the semantic representations of NP and clause (sections 2-3) and identified symmetries and anti-symmetries obtaining among the grammatical categories (ir)realis, (in)definite, and (non)specific (sections 4-7). At this point quite naturally the question arises whether the 
general insights and particular findings reported in the preceding sections can be accorded any significance from a cognitive point of view.

It appears there are two routes into the investigation of cognitive structures. Besides empirical studies of factual cognitive processes there is theoretical inquiry into the range of possible organizations of cognitive domains, which is primarily conducted in an interdisciplinary research area where linguistics and philosophy, or more narrowly: philosophical ontology, overlap. Ontology is the philosophical discipline that devises descriptions of possible structures of the world we experience and speak about. ${ }^{17}$

Since Aristotle ontologists have mainly preferred to take their cues from grammatical facts rather than from descriptions of allegedly 'pure' phenomenal experience. This longstanding methodological conviction that descriptions of conceptual structures should be guided by the analysis of linguistic structures received a strong impulse during the last century. Mainly due to the work of Alfred Tarski, Rudolf Carnap, and Richard Montague the "linguistic turn" (more a 'return to language') in ontology generated fertile research interactions between logic, analytical ontology, and linguistics. Model-theoretic semantics, or more generally, the project of assigning (structural descriptions of) denotations to (classes of) sentences, can be undertaken from a variety of viewpoints and with various theoretical goals. An ontological model theory furnishes assignments of formal structures to (classes of) sentences in order to justify the inferentially relevant part of a language $\mathrm{L}$ in terms of the structure of the 'world of experience' that L-speakers take themselves to talk about. In short, ontology investigates the cognitive (inference-guiding) structures we can attribute to our world of experience in order to understand why we speak and reason about the world the way we do.

In the following four sections we will consider the cognitive implications of the preceding linguistic results from the point of view of analytical ontology. Generally speaking, we will be concerned with the question which of the various possible structural descriptions of the world of experience - i.e. the external, physical world that contains correlates for items in the speaker's and hearer's shared world of discourse - would best account for the stated linguistic results. Due to limitations of space we will confine ourselves to discussing two such 
MOOD, DEFINITENESS AND SPECIFICITY: A LINGUISTIC AND A PHILOSOPHICAL ACCOUNT OF THEIR SIMILARITIES AND DIFFERENCES

structural descriptions. After a brief discussion of the linguistic data in the remainder of this section we will in section 9 point at difficulties arising for any attempt of accommodating these data in an unmodified 'standard possible world framework'. In sections 10 and 11 we motivate and sketch an alternative framework for the interpretation of modal sentences and indefinite NPs, a newly developed ontology called 'General Process Theory' (GPT). GPT contains the theoretical tools to define suitable cognitive structures that can (a) explain the parallels in the semantic representations of NP and clause, and (b) justify the various symmetries and anti-symmetries in the pragmatic status of denotations of (in)definite NPs and clauses in the (ir)realis as detailed above.

Hereafter we will refer to the above noted linguistic Similarities and Differences in Mood and Definiteness by the acronym 'SDMD'. Let us set out with the question whether the SDMD present ontological research with proper 'data', and if so, which aspects of the SDMD are relevant for ontological theory construction.

To restate, in a rough and ready characterization, an ontology is a theory that explains how we reason in terms of what we can take ourselves to reason about. More precisely, the task of an ontology is to describe the structure of the referential domain of a language $\mathrm{L}$ in such a way that the inferential role of Lsentences (in their discourse environment) is captured as fully as possible. In contrast to typical instances of model-theoretic semantics used in linguistics, an ontological theory aims to devise interpretations for L-sentences that are (in the linguistic sense) 'typologically general', i.e., that capture the inferential role of the sentence independent of its specific linguistic coding. In other words, while a linguistic semantics is typically developed for a single language, ontologists aspire to provide descriptive tools for the interpretation of any language. The intended universal scope of an ontology can be conveniently indicated by means of Sellarsian "dot-quotes". A dot-quote term such as '•red•' denotes distributively any expression that is functionally equivalent to the quoted expression. Thus we can state the following general characterization of an ontology:

(ONT) In its perspicuous methodological form an ontological theory has the form of the quadruple 
$<\mathrm{M}, \mathrm{T}_{\mathrm{M}}, \mathrm{f}, S=\left\{\bullet \mathrm{S}_{\mathrm{i}} \bullet\right\}>$

That is, an ontological theory defines (explicitly or implicitly) an assignment $\mathrm{f}$ that correlates the elements of a class $S$ of dot-quoted Lsentences (or L-discourse parts) with elements of the model structure $M$ as described by a domain theory $\mathrm{T}_{\mathrm{M}}$, such that $\mathrm{f}$ captures the (ontologically relevant part of the) inferential role of any $\bullet \mathrm{S}_{\mathrm{i}} \bullet$.

An assignment $f$ captures the inferential role of a sentence $\bullet S_{i} \bullet$, if the cognitive structure $f\left(\bullet S_{i} \bullet\right)$ (i.e., the element in the model structure $M$ ) entails the formal and the most general 'material' inferences licensed (relative to L) by S. For example, the ontological interpretation of '•this car is red $\bullet$ ' should entail the

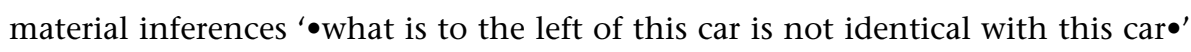
and '•it is not the case that what is to the left of this car is not identical with red $\bullet$ '. Material inferences at this level of generality are called 'categorial inferences'. Thus, in analogy to common characterizations of logical theories as theories of formal inference in $\bullet \mathbf{L} \bullet$, an ontological theory can be called a theory of the categorial inference in $\bullet \mathrm{L} \bullet{ }^{18}$

This characterization of ontology goes beyond the more familiar portrayals of ontologies as "theories of truth-makers" - i.e., entities the existence and constellation of which 'makes true' the sentence of a language. The description we offer here has the advantage of indicating at once what kind of data ontological theories must account for, namely, the categorial inferences embedded in a language (understood as a representative of a functionally equivalent class of languages).

Relative to the definition of ontology in (ONT) the question of whether the SDMD are ontologically relevant transforms into: 'Are there categorial inferences contained in or connected with the SDMD?' For the case of the similarities or symmetries between mood and definiteness this is rather obvious. Consider sentences (31) through (34):

(31) Max sat down

(32) Max would have sat down

(33) Emma was looking for the cup

(34) Emma wants a dog 
MOOD, DEFINITENESS AND SPECIFICITY: A LINGUISTIC AND A PHILOSOPHICAL ACCOUNT OF THEIR SIMILARITIES AND DIFFERENCES

Both (31) and (33) carry an existential presupposition:

(35) There is an action that Max performed

(36) There is a cup Emma is looking for ${ }^{19}$

Similarly, (32) and (34) both fail to license analogous existential statements. In addition, both (32) and (34) entail negated identity statements:

(37) Sitting down is not identical with the action Max performed then and there

(38) What Emma wants is not identical with any specific dog

If the latter two inferences strike one as somewhat trivial, then this is due to the - in itself far from trivial - fact that grammatical categories such as the 'irrealis' (e.g., the 'counterfactual') and '(non-specific) indefinite' already are classifications of expressions relative to (the ontologically relevant part of) their inferential role.

In the case of the anti-symmetry between realis and definiteness matters are quite similar. The inferential significance of the anti-symmetry surfaces via the associated symmetry of clauses in the irrealis and definite NPs: just as there are 'many reasons for being marked as definite, there are many reasons for being marked as irrealis'. This pragmatic similarity between definite NP and irrealis is reflected in an inferential similarity; consider:

(39) Max V-ed the N (e.g.: Max moved the chair)

(40) Max would have V-ed (e.g.: Max would have sat down)

(41) The N V-ed by Max is something that can be re-encountered from different viewpoints

(42) The V-ing by Max is identical with any future, desired, commanded, hoped for etc. $\mathrm{V}$-ing by Max

Sentences (41) and (42) both express that the denotation of the NP or clause, respectively, is something that can be re-encountered - either across discourse time or space as in (41), or across the varieties of modality, as in (42). These two inferences again closely reflect the meaning of the grammatical categories of 'definiteness' and 'irrealis'. Definiteness expresses that type of reidentifiablity that enables factual or possible re-encounters in time and space. Similarly, the 
fact that the irrealis comprises many different modalities dovetails with the inference in (42) that the non-actual event denoted in (40) is cognitively stable across different varieties of non-actuality. The non-actuality of the event, (42) says, expresses that type of re-identifiability that enables identification across discourse contexts.

The implications of the SDMD just highlighted as ontological data appear redundant since they reformulate aspects of the core meaning of the grammatical notions '(ir)realis' and '(in)definite'. However, once the inferential anchoring and thus the ontological relevance of the grammatical categories of mood and definiteness as such has come into view, one can claim that even the more pragmatic aspects of the SDMD are - at least prima facie - ontologically relevant. Already the six categorial inferences highlighted above suffice to maintain that an adequate ontological interpretation of $\bullet \mathbf{L} \bullet$-sentences should not only cover the inferential symmetries contained in the SDMD but should also explain, or be at least compatible with, the coding and grounding principles that involve the relevant grammatical categories. That is, an ontological theory should explain, or at least be compatible with, the following facts:

E1) Inferential symmetries:

E1.1) Clauses with definite NPs and clauses in the realis license existential generalizations.

E1.2) Clauses with non-specific indefinite NPs and clauses in the irrealis, respectively, license negated identity statements involving the NP in its definite form and the clause in the realis, respectively.

E1.3) Clauses with definite NPs and clauses in the irrealis, respectively, license identity statements across time and space or across modal contexts, respectively.

E2) Coding principles:

E2.1) An indefiniteness marker should be used when a NP is introduced into the discourse.

E2.2) Indefiniteness markers can be used to denote grounded and ungrounded entities.

E3) Grounding principles:

E3.1) The realis and specific indefinite NPs 'ground themselves' in discourse directly, without sentential embedding or discourse embedding. 
E3.2) There are many ways to ground an NP and many ways to 'unground' a sentence in discourse.

\section{A CRITICAL LOOK AT POSSIBLE WORLDS}

The refurbishment of Leibniz's notion of a possible world for the purposes of modal logic and probability theory supplied $20^{\text {th }}$ century analytical thought with one of its most important conceptual tools. Many of the most significant achievements of analytical ontology, philosophical logic, and formal semantics pertain to the modeling of reasoning in non-extensional contexts. Given the impressive versatility of the possible world approach, they present the most natural starting point for an inquiry into the ontological interpretation of the SDMD.

For present purposes it will suffice to highlight four basic theoretical moves involved in the adoption of a 'standard possible world semantics,' i.e., of a possible world framework together with usual formal reconstruction of natural language expressions in standard predicate logic. ${ }^{21}$

PW1) There is a (finite or infinite) set $\mathrm{W}$ containing the actual world $\mathrm{w}^{*}$ and possible worlds $\mathrm{w}_{\mathrm{i}}: \mathrm{W}=\left\{\mathrm{W}^{*}, \mathrm{w}_{1} \ldots \mathrm{w}_{\mathrm{n}}\right\}$. Any world $\mathrm{w}_{\mathrm{i}}$ is a (maximal and consistent) set of state of affairs (or things exemplifying properties and relations). The members of $\mathrm{W}$ do not share any elements.

PW2) The denotations of non-grounded NPs and sentences in the irrealis are either (i) possible entities (members of possible worlds) or else (ii) senses or intensions conceived of as functions from possible worlds into extensions. All and only sentences in the realis are true in the actual world. The denotations of grounded NPs are members of the actual world.

PW3) The formal equivalent of linguistic indefiniteness (indefinite NPs) is existential quantification and predication. (For example, the formal analysis of Tom is riding a bicycle should be developed from the transformation There is something which is a bicycle and Tom is riding it).

PW4) The formal equivalent of linguistic definiteness (definite NPs) is existential quantification plus a uniqueness condition. (For example, the formal analysis of the winner should be developed from the transformation There is an $x$ which is a winner and for every $y$ which is a winner it holds that $y$ is identical with $x$ ).

If to these principles one is prepared to add the assumption:

PW5) The shared discourse world is the actual world $\mathrm{w}^{*}$, 
a number of the SDMD-explananda (E1) through (E3) can be smoothly accommodated. For example, consider again:

E1.2) Clauses with non-specific indefinite NPs and clauses in the irrealis, respectively, license negated identity statements involving the NP in its definite form and the clause in the realis, respectively.

The difference between specific and non-specific indefinite NPs corresponds to the logician's distinction of 'de re' and 'de dicto' readings of sentences with indefinite NP:

\section{(43) Max is looking for a bicycle}

\section{De re reading:}

(43a) There is something which is a bicycle and Max is looking for it

\section{De dicto reading:}

(43b) Max is looking for something that satisfies the predicate 'is a bicycle'

The indefinite NPs of sentences in the de dicto reading are taken to denote possible entities or intensions (i.e., properties, conceived of as sets of possible individuals, or functions from possible worlds into sets of actual individuals), just as sentences in the irrealis, see (PW2) denote possible entities or intensions (i.e. propositions, conceived of as sets of states of affairs, or functions from possible worlds into truth-values). Since there is no overlap between the actual and any possible world, the symmetric inference mentioned in (E1.2) holds: anything denoted by non-specific indefinite NPs and clauses in the irrealis will be non-identical with the denotations of grounded NPs and clauses in the realis (see PW2).

On the basis of the postulate that specific indefinite NPs denote actual entities and non-specific indefinite NPs denote possible entities or intensions, the possible world approach also can straightforwardly motivate the NP-part of the grounding principle: 
E3.1) The realis and specific indefinite NPs 'ground themselves' in discourse directly, without sentential embedding or discourse embedding.

The groundedness of the realis follows directly from (PW2) together with the standard truth-condition for the realis.

Furthermore, given the analysis of definiteness as existential generalization with uniqueness requirement, the coding principle:

E2.1) An indefiniteness marker should be used when a NP is introduced into the discourse.

makes good sense in a situation where uniqueness is not yet established (as well as the exceptions mentioned above, e.g., 'the moon' where uniqueness is presupposed). The same holds for the second coding principle:

E2.2) Indefiniteness markers can be used to denote grounded and ungrounded entities.

The possible world framework can accommodate this principle due to the fact that (i) indefinite NPs are represented by existentially quantified predicates (see PW3 above), and (ii) existential quantifiers are defined to range over entities in actual and possible worlds.

While observations such as these suggest that the standard possible world framework could be used for an ontological interpretation of the SDMD, at least one of the SDMD-explananda strongly militates against such a strategy. Consider again:

E1.1) Clauses with definite NPs and clauses in the realis license existential generalizations.

The inferential symmetry of definite NPs and sentences in the realis at first glance seems to correlate well with the fact that the denotations of both are in the actual world - existential generalization over actual entities carries the sense of actual existence. However, this strong sense of existential generalization as 'there is in the actual world ...' would fit only existential generalizations licensed by a sentence in the realis. For definite NPs that intuitively denote non-actual 
entities, the sense of existential generalization obviously cannot be 'there is in the actual world' and thus we lose the inferential symmetry in (E1.1). On the other hand, we cannot adopt the weak reading of existential generalization as 'there is in some world (actual or possible) ...' on pain of losing the contrast with ungrounded NPs (where existential generalization applies in this weak sense precisely). Consider:

\section{(44) Max searched the holy grail}

The NP in (44) is grounded in the discourse world yet intuitively should denote a possible entity or an intension, not a denizen of the actual world. It appears thus that the basic premise (PW5) must be abandoned: the shared discourse world, the world of grounded entities, cannot be equated with the actual world $\mathrm{w}^{*}$ in the possible world framework. But then 'all bets are off again' with respect to the question whether and how any of the SDMD-explananda could be accommodated in a possible world framework.

At this point the natural course of action might seem to embark on the task of investigating possible replacements for (PW5). But it is questionable whether this strategy would at all be worthwhile for the purposes of an ontological interpretation of the SDMD. ${ }^{22}$ So far we have bracketed the question whether the possible world framework is indeed a viable ontological approach. The possible world framework is unquestionably a versatile and useful conceptual tool for many tasks in formal semantics and philosophical logic. But however convenient 'possible world talk' might be as a rough-and-ready clarificatory idiom in these areas, from the ontologist's point of view the conceptual foundations of the possible world framework seem unsatisfactory in at least two ways.

First, if worlds are sets of states of affairs, they are - if we follow the common 'platonist' interpretation of sets - curiously abstract, which does not sit well with the idea that the actual world is one of the possible worlds. The problem receives its particular bite in combination with the following antinomy. ${ }^{23}$ If each possible world is defined as a maximally consistent set of states of affairs $\mathrm{w}=\left\{\mathrm{s}_{1}, \ldots \mathrm{s}_{\mathrm{n}}\right\}$, then for any state of affairs $s_{i}$ consistent with the states of affairs in $w$ it holds that $s_{\mathrm{i}} \in \mathrm{w}$. According to the power set axiom there are $2^{\mathrm{n}}$ subsets of $\mathrm{w}$. Among 
these subsets there is the subset $\left\{\mathrm{s}_{1}, \mathrm{~s}_{2}\right\}$ and the subset $\left\{\mathrm{s}_{3}, \mathrm{~s}_{4}\right\}$. But then there are states of affairs expressed by the statements $s_{1} \in\left\{s_{1}, s_{2}\right\}$ and $s_{1} \notin\left\{s_{3}, s_{4}\right\}$. Call these states of affairs $s_{5}$ and $s_{6}$. Obviously $s_{5}$ and $s_{6}$ are consistent with $\mathrm{w}$ and thus should be elements of $\mathrm{w}$. Thus $\mathrm{w}$ is not maximal, which is in conflict with the original assumption. There are various ways in which this antinomy might be avoided. But they all require that one renounces the framework's basic asset, namely, the postulate (PW1) that possible worlds are sets of states of affairs (in the sense defined by standard set theory where the power set axiom holds). ${ }^{24}$

Second, the possible world idiom obscures difficulties in talking about possibilia. When we want to say that a state of affairs $p$ is possible, we commonly express this with an existential quantification:

(45) $\quad p$ is (merely) possible $=$ there is a world $w$ (which is not the actual world $\left.w^{*}\right)$ and $p$ is a member of $w$. $\diamond p=\exists w(p \in w)$

But the existential quantifier is standardly interpreted over actually existing objects. In other words, standard quantification is actually not comprehensive enough to reach into non-actual entities and worlds. This creates the following dilemma for an understanding of existence and existential quantification ${ }^{25}$ :

A) Assume that in the possible world framework quantification is understood in the usual way and existence as actual existence. This option has the advantage of retaining a reasonable concept of existence, but it does so at the expense of losing the distinction between actual and possible worlds: if the same quantifiers are taken to range over all worlds, and we understand existential quantification in the usual sense as ranging over actually existing entities, then possible worlds would exist as much or in the same sense as the actual world.

B) Assume that in the possible world framework quantification is given a special interpretation, call it "possibilistic quantification". Unlike standard quantifiers 'possibilistic quantifiers' range over possible entities. Here we can retain the distinction between actual and possible worlds, but at the expense of losing the familiar concept of quantification. Moreover, in defining 'possibilistic quantification' as quantification over possible entities, definitions of modal predicates and operators in a possible world framework would hardly be enlightening from the ontological point of view.

In sum, while the possible world idiom affords a handy semantic tool to interpret modal reasoning in terms of set-theoretic structures, it is questionable 
whether these structures can be given any ontological meaning and thus (cf. section 8) attributed any potential cognitive significance. One might opt to push these objections aside and search for suitable replacements for (PW5) above, relating the actual world and the discourse world in more sophisticated ways. However, we think it would seem more natural to react in the opposite way and take the framework's failure vis-à-vis SDMD-explanandum (E1.1) as yet another reason to turn away from the possible world approach and explore other avenues for an ontological interpretation of the SDMD.

\section{Possibilism, ACTUALISM, AND THE MYTH OF SUBSTANCE}

There are two basic strategies for an interpretation (semantic or ontological) of modal discourse. The possible world framework considered in the previous section implements the first strategy, which we call 'possibilism or duplication variation':

\section{Possibilism or Duplication Variation}

Statements about possible entities (events, state of affairs, individuals etc.) are made true by entities in deactualized variations of the actual situation or world (set of actual events, states of affairs, individuals etc.). So-called possible situations or worlds are sets of deactualized entities - the entities in these worlds are as determinate or 'fully fleshed out' as actual entities and merely lack the latters' actuality. The variation scenarios called possible situations or worlds are - in conceptual space - juxtaposed to the actual situation or world.

In contrast, some ontologists have championed the view that modal statements are actually made true by actual entities. ${ }^{26}$ This strategy of 'actualism or embedding' comes in two varieties:

\section{Actualism or Embedding}

Act 1) Statements about possible entities (events, state of affairs, individuals etc.) are made true by abstract actual entities.

Act 2) Statements about possible entities (events, state of affairs, individuals etc.) is talk about possible recombinations of actual entities.

The two versions of actualism have rather obvious drawbacks - version (Act 2) is threatened by circularity, and version (Act 1) is saddled with the obscurity of the abstract. Yet (Act 1) is almost on the right track, which is, we suggest, the following third variety of the actualist strategy: 
Act 3) Statements about possible entities (events, state of affairs, individuals etc.) are made true by indeterminate ('schematic') actual entities.

This third, and as far as we know, new version of actualism is a direct ontological implementation of the grammatical observation about the symmetry between non-specific indefiniteness and irrealis - the grammatical symmetry is here taken to indicate that possible events are like non-specific actual entities. The guiding intuition underlying (Act 3) might be adumbrated as follows: (i) socalled 'possible' individuals such as a unicorn are in the actual world in the same way as 'general individuals,' i.e., individuals denoted by NPs with the "institutional" (generic) use the definite article, as in:

(46) The lion is tawny

(47) The postman delivers the mail

General individuals are functionally defined, thus 'schematic' or partially indeterminate individuals. (ii) Similarly, the hunting of the pig that would have occurred under normal conditions but did not occur, is in the actual world in the same way as the denotations of sailing, running and walking in:

(48) There's good sailing all along the coast

(49) Running is more exhausting than walking

The denoted occurrences are again functionally individuated, thus 'schematic' or partially indeterminate.

The reasons why ontologists so far have paid little attention to functionally individuated entities are, we submit, mainly historical and contingent rather than systematic. The ontological tradition has as its central tenet that substances or objects are the primary category of basic entities. Substances or objects are particular (uniquely located), bounded, countable, concrete individuals - in short, 'thinglike' entities. The assumption that the ontological domain, the world we speak about in natural languages, is most naturally described as an assembly of 'thinglike' entities, is one of the most important elements of a network of presuppositions operative in most historical ontological thought. This presuppositional complex, which we call the "Myth of Substance", can be 
shown to constrain and direct ontological discussion and theory construction to the present day. ${ }^{27}$

The popularity of the 'possibilist' strategy betrays the virulence of the 'Myth of Substance.' If one presumes that the most 'natural' approach to an ontological interpretation of natural language is in terms of thing-like entities or 'classical individuals', i.e., uniquely and definitely located, bounded, and fully determinate individuals, then one will likely assimilate possible entities to such classical individuals, in collections of possible classical individuals 'sitting side by side' with collections of actual classical individuals:

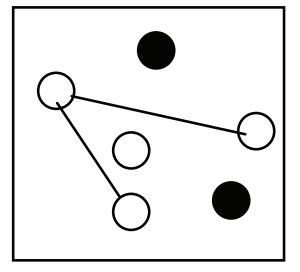

Actual world $\mathrm{W}^{*}$

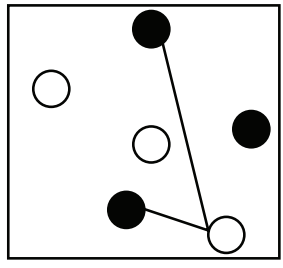

Possible world W1

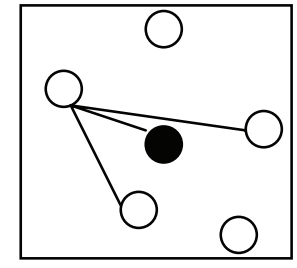

Possible world W2

Figure 8. Possibilia as classical individuals

Similarly, as long as one is in the grip of the presuppositional network of the Myth of Substance, only versions (Act 1) and (Act 2) of the actualist strategy will come into sight, where possible entities are abstract thing-like entities or thinglike combinations of thing-like entities.

Version (Act 3) of the actualist strategy can be recognized as a viable option once one abandons the Myth of Substance and rejects the presumption that individuality must be understood as implying thing-like existence. In its broadest sense, individuality expresses merely distinctness: an individual is a something of which we can say 'this, not that', something we can distinguish from other entities and thus refer to. ${ }^{28}$ Often distinctness is due to location entities that are uniquely and determinately located and thus distinguishable in terms of their location are called 'particular' entities, or briefly: particulars, in ontology. The distinctness of particulars is a type of distinctness we are well familiar with because of its role in ostension, but it is by no means the only type of distinctness. For we also can distinguish one entity from another in terms of 
MOOD, DEFINITENESS AND SPECIFICITY: A LINGUISTIC AND A PHILOSOPHICAL ACCOUNT OF THEIR SIMILARITIES AND DIFFERENCES

its function. Stuffs or masses (milk, water, wood) as well as occurrences we typically individuate in terms of their functional difference rather than in terms of (spatio-temporal) location, as witnessed by:

(50) 'What did you do, when she hit you?' - 'The same'

(51) (Phone conversation) 'It's raining cats and dogs here at the moment' - 'Just the same here'

Such functionally distinguishable entities, which we call functional individuals, can be taken to occur 'superposed' in the actual world:

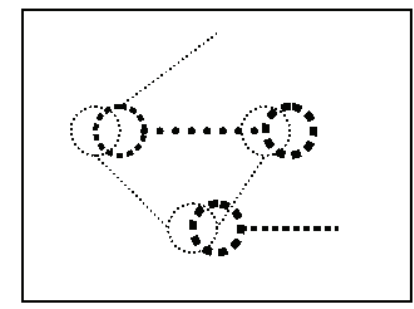

Figure 9. Actual world with 'superposed' functional individuals

Let us now ask to what extent an ontological theory that (i) based on functional individuals and (ii) committed to actualism in version (Act 3), can accommodate the SDMD.

\section{AN ONTOLOGY OF FUNCTIONAL INDIVIDUALS}

To our knowledge there is currently only one ontological framework that combines a commitment to functional individuals with an actualist approach, namely, 'General Process Theory' (hereafter 'GPT'). ${ }^{29}$ For present purposes it will suffice to give a rough and informal sketch of some basic ideas and notions of GPT.

In GPT there is only one sort of basic entities, called 'general processes,' and only one basic generative relation, namely, the 'is part of' relation. A general process is a non-classical individual: a dynamic, concrete, non-particular entity individuated in terms of its functional parts or ingredients. For example, walking, running, and snowing are different individuals, since they have different ingredients of functional parts: 
Parts of walking: lifting right leg, lifting left leg, shifting weight, positioning foot on ground, pushing forward.

Parts of running: lifting right leg, lifting left leg, shifting weight, positioning foot on ground, pushing forward-and-upward.

Parts of snowing: group motion of gliding, group motion of rotational tumbling.

According to GPT the set of individuals comprises entities that we commonsensically classify as occurrences - activities, actions, events, procedures, performances etc. - as well as those entities that we commonsensically classify as things, persons, features, facts, or situations. Thus being-a-table, being-Max, beinggreen, Max's being 6 feet tall, or the Sprogkollokvium are individuals in GPT. In short, according to GPT the domain of $\mathrm{f}(\bullet \mathrm{L} \bullet)$ consists of nothing else but functionally individuated entities of various sorts and complexity.

Functional individuals occur in many ways in space and time. For our purposes here it will suffice to consider three notions of spatio-temporal occurrence, which we will introduce here informally as three species of (spatial and/or temporal) situatedness.

Being in some region

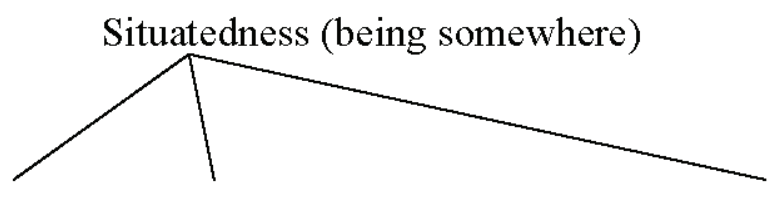

being in some bounded region

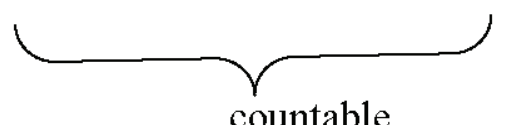

Figure 10. Types of situatedness in GPT

Spacetime - and that is: not only geometrical space but also the space of common sense reasoning - has a topological description in terms of bounded and unbounded regions and a metrical description in terms of places and time spells, i.e., intervals defined on co-ordinates that are bounded regions. According to type of situatedness, functional individuals can be attributed indefinite or definite locations (in space or time): 


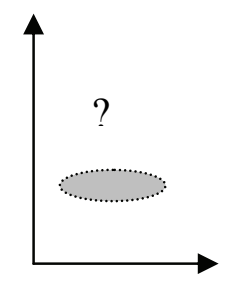

Indefinitely located in space and time

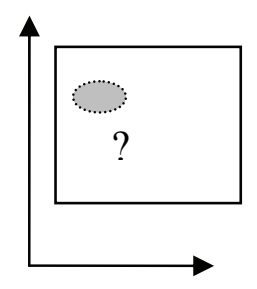

Indefinitely located in a bounded region

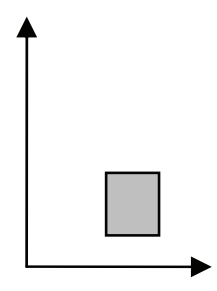

Definitely located in a place

Figure 11. Differently situated individuals

It is crucially important to note that countability is not restricted to entities with definite locations, as the ontological tradition has it. We can count entities not only when they occupy different places, i.e., different bounded regions R1 and $\mathrm{R} 2$, but also when we know that they occupy each some bounded region (and that these two regions, wherever they may be, are not connected).

On the basis of the mentioned distinctions in situatedness we can now introduce three classificatory predicates for functional individuals. First the basic predicate of being an individual that holds for all basic entities in GPT:

D0) $\quad \alpha$ is an individual iff $\alpha$ has situatedness

Individuals are concrete, they are somewhere, but they may occur in a unique location or distributed over a region (little bits here and there) or, most importantly, 'smeared out' over a region, that is, simply in a region in an unbounded fashion. For example, sentences (52) through (54) denote concrete, yet indefinitely located entities (water, music, running):

(52) Water is going to be a rare commodity in 2050

(53) Slow music reduces bodily tension

(54) Running is good for your lungs and bad for your knees

Indefinitely located, non-countable (stufflike) individuals as denoted by sentences (52) through (54) are called merely occurrent individuals:

D1) $\alpha$ is a merely occurrent individual iff $\alpha$ is indefinitely located. 
Some functional individuals, though not definitely located, have a type of situatedness that allows us to count them:

D2) $\alpha$ is a quantity of $\beta$ iff $\alpha$ has the same functional features as $\beta$ and $\alpha$ occupies a bounded region.

For example, sentences (55) and (56):

(55) Emma did two times ten minutes of biking today

(56) There are at least three liters of beer in this keg

state that certain quantities of biking and quantities of beer, respectively, occur in certain temporal or spatial regions (this day, this keg). A quantity occupies a bounded region, otherwise we could not count it, yet it is not determinately located in this bounded region. Somewhere twice within the spell of this day a ten minute biking event occured, and somewhere in this keg (not 'next to each other'!) there are three liters of beer.

Other individuals can be counted and occupy a place (i.e. a definite bounded region which is also an interval of spatial coordinates). Being in a place is the kind of situatedness we are familiar with from classical individuals.

D3) $\alpha$ is an amount of $\beta$ iff $\alpha$ has the same functional features as $\beta$ and $\alpha$ occupies a place.

For example, the following sentences denote individuals that are amounts of individuals:

(57) This glass of wine was the best

(58) Kim saw John at the corner

(59) Kim's wedding lasted only ten minutes

Altogether then the class of functional individuals contains three nonoverlapping subclasses of individuals, only two of which contain individuals with a type of locatedness that makes them countable ${ }^{30}$ : 


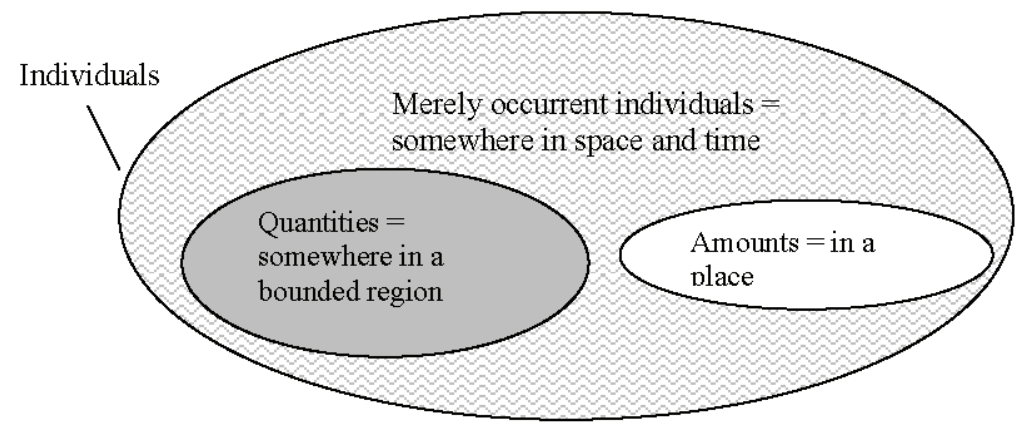

Figure 12. Types of GPT-individuals

Let us now put these definitions to use for an ontological interpretation (explanation) of the SDMD-explananda, beginning with the GPT rephrasal of the actualist postulate (B3) above:

\section{Act-3-in-GPT}

The actual world consists of collections of concrete, dynamic, nonparticular individuals ('general processes') of varying complexity, (in)specificity or (in)determinateness, and different types of (in)definite locations. The 'shared world of discourse' is a collection of processes in the actual world.

Given that sentences in the realis and definite NPs denote functional individuals that have a definite place in the discourse world, their ontological correlates in GPT will be individuals that are amounts of individuals (marking the ontological interpretation function by ' \|\|$^{\prime}$ ):

(60) $\|$ The farmers killed the pig\| $=\alpha=$ Amount of (killing of (amount of being-pig) by (amount of beingfarmer))

(61) $\|$ John read the book\| $=\beta=$ Amount of (reading of (amount of being-book) by (amount of beingJohn))

Also specific indefinite NPs are assigned amounts as ontological correlate:

(62) \|John was reading a book when I came in $\|$ $=\gamma=$ Amount of (reading of (amount of being-book) by (amount of beingJohn))... 
In contrast, the ontological correlates of sentences in the irrealis and nonspecific indefinite NPs are (actual!) individuals without definite location, that is, merely occurrent individuals as defined in (D1), or quantities as defined in (D2). If there are no grammatical or contextual restrictions on location, the ontological correlates are merely occurrent individuals, e.g., the occurrence ('types') reading, being a book, wanting, or being a dog in (63) and (64), respectively:

(63) \|if John only read a book sometime! \|

$=\delta=$ reading of (being-book) by amount of (being-John)

(64) ||John wants a dog $\|$

$=\eta=$ Amount of (wanting (being-dog) by (amount of being-John))

Whenever the sentence frame or the context introduce spatial or temporal boundaries, thus restricting the indefinite location to certain bounded regions, as in sentences (65) and (66), the ontological correlates are quantities:

(65) ||John would have read the book if he had not taken ill $\|$

$=\varepsilon=$ quantity of (reading of (amount of being-book) by (amount of beingJohn))

(66) \|John is asking for a cup $\|$

$=\theta=$ Amount of (asking for (quantity of (being-cup) by (amount of beingJohn))

GPT allows us in this way to create an 'ontological mirror image' of sorts for the above highlighted discourse-pragmatic similarity of realis and definite NPs on the one hand, and of irrealis and non-specific indefinite NPs on the other hand. To state the assignment rules that generate the illustrations (60) through (66) just given:

R1) The ontological correlates of specific definite NPs, indefinite NPs, and clauses in the realis are amounts of individuals.

R2) The ontological correlates of non-specific indefinite NPs and clauses in the irrealis are merely occurrent individuals or quantities of individuals. 
With these assignment rules the inferential the SDMD-explananda are easily accounted for. Consider again explananda (E1.1) and E1.2):

E1.1) Clauses with definite NPs and clauses in the realis license existential generalizations.

E1.2) Clauses with non-specific indefinite NPs and clauses in the irrealis, respectively, license negated identity statements involving the NP in its definite form and the clause in the realis, respectively.

The existential generalization in (E1.1) has the force of 'there is one, countable, determinately placed entity', which is implied by (R1) and the definition of an amount of an individual (D3) above. (E1.2) can be traced to the fact that the ontological correlates in question, quantities or merely occurrent individuals, differ from amounts. Also the coding principles:

E2.1) An indefiniteness marker should be used when introducing a NP into the discourse.

E2.2) Indefiniteness markers can be used to denote grounded and ungrounded entities.

appear well-motivated on the suggested interpretation. Indefinite NPs (a meeting, a book) may denote all three: 'mere' indefinitely located individuals (meeting, being a book), quantities (a meeting of two hours, a book in this room), or amounts (our meeting this morning, the book I just pointed at), and it makes good sense to use a linguistic coding that signals a range of ontological alternatives, an 'ontological disjunction' as it were, before the sentential context establishes which alternative is relevant. The grounding principle:

E3.1) Realis and specific indefinite NPs 'ground themselves' directly, without sentential embedding or discourse embedding

follows directly from (R1) and a reading of grounding as having definite location or being placed - the reading that naturally fits the sense of the existential generalization in (E1.1) just mentioned. Finally, consider the anti-symmetry of realis and definite NPs, which is manifested in the inferential symmetry

E1.3) Clauses with definite NPs, and clauses in the irrealis, respectively, license identity statements across time, or across modal contexts, respectively, 
and the related grounding principle:

E3.2) There are many ways to ground an NP and many ways to unground a sentence, turning it into an irrealis.

On the suggested ontological interpretation in terms of actual functional individuals these two principles do not directly follow from (R1) or (R2), but within an ontology of functional individuals such as GPT they appear well motivated at least. That definite NPs and irrealis display at all the communalities mentioned in (E1.3) and (E3.2) can be traced to the fact that some forms of reidentification require that we focus on features of location (across time and space), while others require that we focus on functional features only (across modal contexts). In order to prep a functional individual for re-identification across time and space, it must be definitely localized; in order to prep a functional individual for re-identification across modal contexts, it must conversely be 'stripped' of such definite situatedness. If both NPs and clauses are interpreted as functional individuals, the ontology itself already prefigures such flexibility in focus ('localization' vs. 'functionalization' of a feature) as required by various types of re-identification - the grounding and ungrounding of both NPs and clauses is in each case a matter of specifying or despecifying location (localizing or functionalizing a feature). ${ }^{31}$ In this connection it is important to note that in our view localization in a definite place must not be understood as implying causal contact. In the suggested actualist setting fictional and imaginary entities denoted by definite NPs or the realis (e.g., the denotation of Sherlock Holmes lives on Baker St. or John searches the holy grail) are as definitely localized as denotations of definite NPs and clauses in the realis that are nonimaginary or non-fictional - the only difference is that the latter are, by the participants of a discourse, agreed to stand in direct causal relationships amongst themselves and with discourse participants. ${ }^{32}$ 
MOOD, DEFINITENESS AND SPECIFICITY: A LINGUISTIC AND A PHILOSOPHICAL ACCOUNT OF THEIR SIMILARITIES AND DIFFERENCES

\section{REFERENCES}

Armstrong, David M. (1997), A world of states of affairs, New York: Cambridge University Press.

Baker, Mark, Lisa Travis (1997), "Mood as verbal definiteness in a 'tenseless' language", Natural Language Semantics, 5 (1997), pp. 213-269.

Bringsjord, Selmer (1985), "Are there set-theoretic possible worlds?" Analysis, 45 (1985), p. 64.

Butler, Christopher S. (2003), Structure and function - A guide to three major structural-functional theories, part 1, Approaches to the simplex clause, part 2, From clause to discourse and beyond (Studies in Language Companion Series 63), Amsterdam: Benjamins.

Bybee, Joan, S. Fleischman (eds.) (1995), Modality in grammar and discourse, Amsterdam: Benjamins.

Chappell, Hilary, William McGregor (1989), "Alienability, inalienability and nominal classification", in: Hall, Kira et al. (eds.) (1989), Proceedings of the Fifteenth Annual Meeting of the Berkeley Linguistics Society, February 18-20, 1989, Berkeley: Berkeley Linguistics Society, pp. 24-36.

Chung, Sandra, Alan Timberlake (1985), "Tense, aspect, and mood", in: Shopen, Timothy (ed.) (1985), Language typology and syntactic description, vol. III, Grammatical categories and the lexicon, Cambridge: Cambridge University Press, pp. 202-258.

Claudi, Ulrike, Bernd Heine (1986), "On the metaphorical basis of grammar", Studies in Language, 10/2 (1986), pp. 297-335.

Craig, Colette Grinevald (1977), The structure of Jacaltec, Austin: University of Texas Press.

Dik, Simon C. (1997), The theory of Functional Grammar ( $2^{\text {nd }}$ revised edition, edited by Kees Hengeveld), part 1, The structure of the clause, part 2, Complex and derived constructions, Berlin / New York: Mouton de Gruyter.

Dimmendaal, Gerrit Jan (1995), "The emergence of tense marking in the NiloticBantu borderland as an instance of areal adaptation", in: Zima, Petr (ed.) (1995), Time in language, Prague: Institute for Advanced Studies at Charles University and the Academy of Sciences of the Czech Republic, pp. 29-43.

Du Feu, Veronica M. (1987), "The determinants of the noun in Rapanui", Journal of the Polynesian Society, 96 (1987), pp. 473-495.

Du Feu, Veronica M. (1989), "Verbal parameters expressed in the NP in Rapanui", Paper presented at the Colloquium on NP Structure, University of Manchester (UK), September 1989.

Du Feu, Veronica (1996), Rapanui, London / New York: Routledge.

Elliott, Jennifer R. (2000), "Realis and irrealis: forms and concepts of the grammaticalization of reality", Linguistic Typology, 4/1 (2000), pp. 55-90.

Enç, Mürvet (1991), "The semantics of specificity", Linguistic Inquiry, 22 (1991), pp. 1-25. 
Epstein, Richard (2002), "The definite article, accessibility, and the construction of discourse referents", Cognitive Linguistics, 12/4 (2002), pp. 333-378.

Fauconnier, Gilles (1985), Mental spaces: aspects of meaning construction in Natural Language, Cambridge: MIT Press.

Fauconnier, Gilles, Mark Turner (2002), The way we think: conceptual blending and mind's hidden complexities, New York: Basic Books.

Felt, James W. (1996), "Why possible worlds aren't", Review of Metaphysics, 50 (1996), pp. 63-77.

Fox, Barbara A., Sandra A. Thompson (1990), "A discourse explanation of the grammar of relative clauses in English conversation", Language, 66/2 (1990), pp. 297-316.

Frajzyngier, Zygmunt (1977), "The plural in Chadic", in: Newman, Paul, Roxana Ma Newman (eds.) (1977), Papers in Chadic linguistics, Leiden: Afrika Studiecentrum, pp. 37-56.

Frajzyngier, Zygmunt (1997), "Grammaticalization of number: from demonstratives to nominal and verbal plural", Linguistic Typology, 1/2 (1997), pp. 193-242.

von Garnier, K. (1909), "COM- als perfektierendes Praefix bei Plautus, SAM- im Rigveda, CYN- bei Homer", Indogermanische Forschungen, 25 (1909), pp. 86109.

Gildea, Spike (1993), "The development of tense markers from demonstrative pronouns in Panare (Cariban)", Studies in Language, 17/1 (1993), pp. 53-73.

Grim, Patrick (1984), "There is no set of all truths", Analysis, 44 (1984), pp. 206208.

Grim, Patrick (1986), “On sets and worlds: reply to Menzel”, Analysis, 46 (1986), pp. 186-191.

Haddican, Bill (2002), "Aspects of DP word order across creoles", paper presented at the CUNY/SUNY/NYU linguistics Mini-Conference, April 20, 2002. [Abstract available at: http://www.nyu.edu/gsas/dept/lingu/events/minico02/ abstract/haddican.pdf].

Halliday, Michael A.K., Christian M.I.M. Matthiessen (2004), Introduction to Functional Grammar (third edition), London: Arnold.

Harder, Peter (1996), Functional semantics: a theory of meaning, structure and tense in English, Berlin/New York: Mouton de Gruyter.

Haspelmath, Martin (1997), From space to time: temporal adverbials in the world's languages, München: Lincom Europa.

Hawkins, John A. (1978), Definiteness and indefiniteness. A study in reference and grammaticality prediction, London: Croom Helm.

Hawkins, John A. (1983), Word order universals, New York: Academic Press.

Heine, Bernd (1997), Cognitive foundations of grammar, Oxford: Oxford University Press. 
MOOD, DEFINITENESS AND SPECIFICITY: A LINGUISTIC AND A PHILOSOPHICAL ACCOUNT OF THEIR SIMILARITIES AND DIFFERENCES

Hengeveld, Kees (2004), "The architecture of a Functional Discourse Grammar" + "Epilogue", in: Mackenzie, J.L., M.A. Gómez González (eds.) (2004), A new architecture for Functional Grammar, Berlin / New York: Mouton de Gruyter, pp. $1-21+$ pp. $365-378$.

Hengeveld, Kees, J. Lachlan Mackenzie (forthcoming), Functional Discourse Grammar, Oxford: Oxford University Press.

Hengeveld, Kees, Jan Rijkhoff, Anna Siewierska (2004), "Parts-of-speech systems and word order", Journal of Linguistics, 40/3 (2004), pp. 527-570.

von Heusinger, Klaus (1999), "Spezifizität als semantische Kategorie", Habilitationsvortrag vorgetragen am 23.6.1999 an der Philosophischen Fakultät der Universität Konstanz.

von Heusinger, Klaus (2002a), "Specificity and definiteness in sentence and discourse structure", Journal of Semantics, 19 (2002), pp. 209-211.

von Heusinger, Klaus (2002b), "The cross-linguistic implementations of specificity", in Jaszczolt, K., Ken Turner (eds.) (2002), Meanings through language contrast, vol. 2, Amsterdam: Benjamins, pp. 405-421.

Kamp, Hans (2004), "Specific-indefinites and anchored logical form", Paper presented at Copenhagen Determination Symposium, Copenhagen Business School (Denmark), 26. August 2004.

Karttunen, Lauri (1976), "Discourse referents", in: McCawley, James D. (ed.) (1976), Notes from the linguistic underground, New York: Academic Press, pp. 363-387.

Kimball, Geoffrey D. (1991), Koasati grammar, Lincoln: University of Nebraska Press.

Kutsch Lojenga, Constance (1994), Ngiti: a Central-Sudanic language of Zaire, Köln: Köppe.

Lehmann, Christian (1995), Thoughts on grammaticalization, München: Lincom Europa.

Levebvre, Claire (1998), "Multifunctionality and variation among grammars: the case of the determiner in Haitian and in Fongbe", Journal of Pidgin and Creole Languages, 13/1 (1998), pp. 93-150.

Lyons, Christopher (1999), Definiteness, Cambridge: Cambridge University Press.

Marchese, Lynell (1986), Tense/aspect and the development of auxiliaries in Kru languages, Arlington, TX: Summer Institute of Linguistics and University of Texas.

McCool, G.J. (1993), "The French demonstrative system: from Old to Modern French", Word, 44 (1993), pp. 31-40.

Menzel, Christian (1986), "On set-theoretic possible worlds," Analysis, 46 (1986), pp. 68-72.

Mithun, Marianne (1988), "Lexical categories and the evolution of number marking", in: Hammond, Michael, Michael Noonan (eds.) (1988), Theoretical morphology: approaches in modern linguistics, New York: Academic Press, pp. 211-234. 
Moravcsik, Edith (1997), "Parts and wholes in the Hungarian noun phrase: a typological study", in: Palek, Bohumil (ed.) (1997), Item order in natural languages. Proceedings of LP '94, Prague: Charles University Press, pp. 307-324.

Newman, Paul (1990), Nominal and verbal plurality in Chadic, Dordrecht: Foris.

Nolt, John (1986), “What are possible worlds?”, Mind, 95 (1986), pp. 432-445.

Nordlinger, Rachiel, Louisa Sadler (2004), "Nominal tense in cross-linguistic perspective", Language, 80/4 (2004), pp. 776-806.

Palmer, F.R. (1986), Mood and modality, Cambridge: Cambridge University Press.

Plantinga, Alvin (1989), The nature of necessity, Oxford: Clarendon.

Prince, Ellen F. (1981), "Toward a taxonomy of Given-New information", in: Cole, Peter (ed.) (1981), Radical pragmatics, New York: Academic Press, pp. 223-255.

Rijkhoff, Jan (1988), "A typology of operators", Working Papers in Functional Grammar 29, Amsterdam: Department of Linguistics, University of Amsterdam.

Rijkhoff, Jan (1989), "The identification of referents", in: Connolly, John H., Simon C. Dik (eds.) (1989), Functional Grammar and the computer, Dordrecht: Foris, pp. 229-246.

Rijkhoff, Jan (1990), "Toward a unified analysis of terms and predications", in: Nuyts, Jan, A. Machtelt Bolkestein, Co Vet (eds.) (1990), Layers and levels of representation in language theory: a functional view, Amsterdam: Benjamins, pp. 165-191. [Reprinted in: Anstey, Matthew P., J. Lachlan Mackenzie (eds.) (2005), Crucial readings in Functional Grammar, Berlin / New York: Mouton de Gruyter, pp. 47-78]

Rijkhoff, Jan (2002 [2004]), The noun phrase, Oxford: Oxford University Press.

Rijkhoff, Jan (2004), “Iconic and non-iconic word order patterns: on symmetry in the NP and counter examples to Universal 20", in: Aertsen, Henk, Mike Hannay, Rod Lyall (eds.) (2004), Words in their places: a Festschrift for J. Lachlan Mackenzie, Amsterdam: Free University, Faculty of Arts, pp. 169-180.

Rijkhoff, Jan (forthcoming), "Layering and iconicity in the noun phrase: descriptive and interpersonal modifiers".

Roberts, John R. (1990), "Modality in Amele and other Papuan languages", Journal of Linguistics, 26 (1990), pp. 363-401.

Schroeder, Christoph (1999), The Turkish nominal phrase in spoken discourse, Wiesbaden: Harrassowitz.

Seibt, Johanna (1996), "Existence in time: from substance to process", in: Faye, J. et al. (eds.) (1996), Perspectives on Time, Dordrecht: Kluwer, pp. 143-182.

Seibt, Johanna (2000), "Ontological categories: the explanation of categorial inference", in: Peres, C., D. Greimann (eds.) (2000), Wahrheit-Sein-Struktur: Auseinandersetzungen mit Metaphysik, Hildesheim: Olms, pp. 272-298.

Seibt, Johanna (2003), "Free Process Theory: towards a typology of occurrings", in: Seibt, Johanna (ed.) (2003), Process theories: cross-disciplinary studies in dynamic categories, Dordrecht: Kluwer, pp. 23-55. 
Seibt, Johanna (2004), General processes - A study in ontological category construction. Habilitationsschrift at the University of Konstanz, Germany.

Seiler, Hansjakob (1978), "Determination: a functional dimension for interlanguage comparison", in: Seiler, Hansjakob (ed.) (1978), Language universals: papers from the conference at Gummersbach / Cologne, Germany, October 3-8, 1976, Tübingen: Narr, pp. 301-328.

Stokes, Bronwyn (1982), A description of Nyigina, a language of the west Kimberley, Western Australia, Ph.D. dissertation, Australian National University.

Strawson, Peter F. (1959), Individuals - An essay in descriptive metaphysics, London: Methuen.

Ultan, Russell (1978), "The nature of future tenses", in: Greenberg, Joseph H. et al. (eds.) (1978), Universals of human language, vol. 3, Word structure, Stanford: Stanford University Press, pp. 83-123.

Van Valin, Robert D. Jr., Randy J. La Polla (1997), Syntax: structure, meaning and function, Cambridge: Cambridge University Press.

Zaefferer, Dietmar (2001), "Modale Kategorien", in: Haspelmath, Martin et al. (eds.) (2001), Language Typology and Linguistic Universals - an international handbook, vol. 1, Berlin / New York: Walter de Gruyter, pp. 784-816.

Zemach, Eddie M. (1970), "Four ontologies", The Journal of Philosophy, 67 (1970), pp. 231-247.

\section{NOTES}

1 See e.g. Craig (1977: 93), Ultan (1978: 101), Du Feu (1987, 1989, 1996), Rijkhoff (1988: 25; 1990: 178), Lefebvre (1998: 94, 99), Baker and Travis (1997).

2 Abbreviations: 3 = third person, $\mathrm{A}=$ adjective, $\mathrm{ALLAT}=$ allative, $\mathrm{ABS}=$ absolutive, $\mathrm{ASP}=$ aspect, CLF $=$ classifier, COUNTERF $=$ counterfactual, DEM $=$ demonstrative, DET $=$ determiner, DS = different subject, $\mathrm{EXH}=$ exhortative, $\mathrm{FUT}=$ future, HORT = hortative, $\mathrm{IMP}=$ imperative, $\mathrm{INF}=$ infinitive, $\mathrm{IRR}=$ irrealis, $\mathrm{N}=$ noun, $\mathrm{NEG}=$ negative, NONFUT $=$ nonfuture, $\mathrm{NP}=$ noun phrase, num $=$ numeral, $\mathrm{PERF}=$ perfective, $\mathrm{PL}=$ plural, $\mathrm{PRES}=$ present, $\mathrm{PROH}=$ prohibitive, $\mathrm{R}=$ realis, $\mathrm{REM} \cdot \mathrm{PAST}=$ remote past, $\mathrm{RSM}=$ resumptive marker, $\mathrm{SG}=$ singular, $\mathrm{SIM}=$ simultaneous.

3 The division between the descriptive and interpersonal function corresponds more or less to information specified at the representational and the interpersonal level in Functional Discourse Grammar (Hengeveld 2004a, 2004b). Note, however, that we use 'interpersonal' in a more restricted sense in that it refers to the pragmatic status of entities in the world of discourse. In Halliday's grammar the interpersonal component ('clause as exchange') mostly serves to express social relations (see Butler 2003 for a detailed comparison of Dik's Functional Grammar (Dik 1997), Hengeveld's Functional Discourse Grammar (Hengeveld 2004, Hengeveld \& Mackenzie forthcoming), Van Valin's Role and Reference Grammar (Van Valin \& La Polla 1997) and Halliday's Systemic Functional Grammar (Halliday and Matthiessen 2004)).

4 Rijkhoff (2004 and forthcoming) proposes a separate descriptive layer inside the quality layer to accommodate what we might call classifying modifiers (cf. Halliday and Matthiessen 2004: 311-335) such as urban in urban hero, Liverpool in Liverpool accent or social in social security (see also Quirk et al. 1985: 1339f, Chappell and McGregor 1989). 
5 Notice that Zande [dem A N num], Berbice Dutch Creole, Bislama, Sranan [num A N dem] and Sango [A N num dem] all constitute counter examples to Hawkins's claim that the adjective never precedes the head when the demonstrative or numeral follow (Universal 20').

6 The reverse direction of development has been proposed by Frajzyngier (1977) for Chadic and Mithun (1988) for a number of North American languages.

7 A relationship between interpersonal modifiers in the NP and the clause is also attested in e.g. Rapanui and Koasati. Rapanui he is used to mark both 'indefinite action' (-tense) and nonspecificity (Du Feu 1987, 1989, 1996). Koasati has five 'article suffixes'. These suffixes serve to "locate a noun in time and indicate that it was previously mentioned": -:sáya 'the aforesaid', -:yólli 'the very', -:ka 'the long ago', -:kitta 'the former', and -o:to 'the deceased; the long ago' (Kimball 1991: 405). Four of these are identical to the participial suffixes (-:sáya 'present participle', -:yólli 'habitual participle', -:ka 'preterite participle', and -:kitta 'imperfect participle'). There is no participial suffix corresponding to -o:to, nor is there an article corresponding to the future participle. See Nordlinger \& Sadler (2004) for a recent discussion of aspect/tense/mood marking on nominals.

8 There is no consensus on the status of specificity as an independent grammatical category (von Heusinger 2002a). For some it is, whereas for others specificity is a subcategory of 'indefinite'.

9 This is not the place to discuss the status of referents, i.e. whether speakers refer to entities in the external, physical world or to mental representation of entities that exist in the/a world of discourse. For the sake of the argument we will simply assume that in a normal conversation speaker and hearer set up a shared world of discourse in which realis clauses are used to refer to events that are deemed to have a correlate in the external, physical world and in which irrealis clauses are used to refer to events that may or may not have a counterpart in the external world. See sections 8-11 for more discussion of the ontological aspects of these issues.

10 Perhaps it is good to emphasize that both the realis/irrealis distinction and the definite/indefinite distinction are also relevant for languages in which these grammatical notions are not expressed by special markers in the NP or clause. For example, in many languages definiteness is marked through syntax (e.g. first position in the clause), phonology or morphology (e.g. case marker on the NP or crossreferencing morphology on the verb). To give an example of phonological marking, in Ossetic definiteness was indicated by shifting the stress to the second syllable (probably due to the incorporation of an erstwhile definite article, cf. Abaev 1964: 12). Schroeder (1999: 40-45) offers a detailed overview of the ways in which definiteness is coded in the Turkish language (which has no definite article).

11 As we will see in section 7, the use of yet is due to referents of indefinite NPs with specific reference, e.g. I saw a dog. Once the specific referent of $a$ dog has been introduced in the world of discourse, it will have a certain place in that world of discourse. On the other hand, once the referent of a nonspecific-indefinite NP has been introduced in the world of discourse, it will exist in that world of discourse, but it does not occupy a particular spatio-temporal region in that world of discourse (e.g. $a$ dog in I want a dog, when any dog will do, no dog in particular is being referred to).

12 Reiterated in Rijkhoff (2002: 234 fn. 31); see also Harder (1996: 280) and Baker and Travis (1998: 242).

13 Notice that nonspecificity and irrealis tend to co-occur in certain contexts, e.g. in the imperative: Give me a spoon!.

14 Cf. Von Heusinger (2002a: 2): “[...] specificity [...] is [...] to be characterized as the property of an NP being referentially anchored".

15 The difference between referents of specific and nonspecific-indefinite NPs may also have to do with the fact that in the case of nonspecific reference we need to set up 
separate discourse worlds for the various interlocutors (rather than having just one shared world of discourse for both speaker and hearer; cf. Kamp 2004).

16 See also Palmer (1986: chapter 6) on modality and other categories.

17 A note for philosophers: The conception of ontology we endorse is inspired by Carnap's idea of a metaphysically neutral investigation into possible structuralizations of the 'world of experience' in the loosely Kantian sense that contrasts with 'reality-initself'. Unfortunately the terms 'ontology' and 'metaphysics' are frequently used interchangeably. We follow what we believe is the historically informed usage where the term 'metaphysics' is reserved for the inquiry into the relationship between the 'world of experience' (the 'external, physical' world, as well as feelings, moods, impressions, and thoughts language users take themselves to be interacting with) and 'reality-in-itself' (e.g., as described by science). Ontology, on the other hand, is the enterprise of exploring possible categorizations (i.e., structural descriptions) of the world of experience without adjudicating the latter's metaphysical status in the 'idealism-realism' controversy as 'mere construction' or 'causally founded construction' or 'the only reality we can reasonably talk about' etc.

18 For details compare Seibt (2000).

19 We omit here consideration of the 'de dicto' reading of (33).

20 The use of variables in these examples is to highlight that the inferred possibility of reencounter is not due to the lexical meaning of particular NPs or clauses.

21 Note that common introductions do not make explicit reference to grounded and nongrounded NPs - this is a characterization we supply.

22 As witnessed by the development of Discourse Representation Theory, and recent variants thereof, at least some formal semanticists have answered this question 'no,' for reasons that are partly unrelated to the difficulty highlighted here.

23 Cf. Grim (1984), (1986), Bringsjord (1985).

24 Cf. Menzel (1996).

25 Cf. Nolt (1985).

26 Cf. Plantinga (1989) and Armstrong (1997).

27 Cf. Seibt (1990, 1996, 2005).

28 Cf. Strawson (1959).

29 Seibt (2004). An ontology based on concrete functional individuals is also envisaged in Zemach (1970). There are two further reasons, besides the SDMD, why an ontology based on functional individuals should deserve particular interest from the linguist's point of view. (1) The order of embedding of descriptive modifiers in the layered model (cf. p. 3 above), and in particular the fact that location and quantity modifiers operate on quality modifiers can be taken as an indication that the primary denotation of clause and NP should not be modeled ontologically as a (thing-like) classical individual, but as a functional individual, i.e., as something that is not 'prepackaged' into countable units. (2) If linguistic evidence for 'localism' suggests that spatial metaphors are used to express temporal and other non-spatial relations, the ways for a concrete entity to exist in space must be diverse enough to support a sufficiently large number of conceptual metaphors. Classical individuals exist in only one way in space, namely, by having a unique, bounded location. In contrast, functional individuals exist in many ways in space: by having a unique, bounded location (occurring in a place) but also by having unbounded location (occurring in a region), and by having multiple locations (being spatially recurrent). For example, a functional individual like water or snowing can occur in a place (bounded, unique location: an amount (portion) of water or snowing), or in a region (unbounded location: a quantity - This bowl of water contains at least 1 liter of water), or can be spatially recurrent (All guests had wine for dinner). 
JAN RIJKHOFF AND JOHANNA SEIBT

30 Note that the GPT predicate ' $x$ is an amount of $y$ ' does not ensure that the individuals fulfilling it (e.g., the denotation of the first landing on the moon) are determinate in all their features, like classical individuals. This additional requirement is met by individuals that fulfill the GPT-predicate ' $\mathrm{x}$ is a portion of $\mathrm{y}$. '

31 The fact that a clause but not an NP can ground itself (that the NP requires the context of a clause to do so) might seem to militate against the idea to assign both to NPs and clauses as ontological correlates 'individuals'. To explain why this is so, e.g., in which way this can be attributed to the difference in complexity of the correlated individuals (my reading a book now vs being this book) is one of the outstanding tasks for the suggested ontological interpretation.

32 GPT lends itself naturally as an ontological framework to be combined with the theory of mental spaces and conceptual blending, cf. Fauconnier (1985), Fauconnier and Turner (2002). 